\title{
Accelerometer Sensor Specifications to Predict Hydrocarbon Using Passive Seismic Technique
}

\author{
M. H. Md Khir, ${ }^{1}$ Atul Kumar, ${ }^{1}$ and Wan Ismail Wan Yusoff ${ }^{2}$ \\ ${ }^{1}$ Department of Electrical and Electronic Engineering, Universiti Teknologi PETRONAS, Bandar Seri Iskandar, \\ 31750 Tronoh, Perak, Malaysia \\ ${ }^{2}$ Department of Geosciences, Universiti Teknologi PETRONAS, Bandar Seri Iskandar, 31750 Tronoh, Perak, Malaysia
}

Correspondence should be addressed to M. H. Md Khir; harisk@petronas.com.my

Received 18 December 2015; Revised 14 April 2016; Accepted 26 April 2016

Academic Editor: Rui Tang

Copyright (c) 2016 M. H. Md Khir et al. This is an open access article distributed under the Creative Commons Attribution License, which permits unrestricted use, distribution, and reproduction in any medium, provided the original work is properly cited.

\begin{abstract}
The ambient seismic ground noise has been investigated in several surveys worldwide in the last 10 years to verify the correlation between observed seismic energy anomalies at the surface and the presence of hydrocarbon reserves beneath. This is due to the premise that anomalies provide information about the geology and potential presence of hydrocarbon. However a technology gap manifested in nonoptimal detection of seismic signals of interest is observed. This is due to the fact that available sensors are not designed on the basis of passive seismic signal attributes and mainly in terms of amplitude and bandwidth. This is because of that fact that passive seismic acquisition requires greater instrumentation sensitivity, noise immunity, and bandwidth, with active seismic acquisition, where vibratory or impulsive sources were utilized to receive reflections through geophones. Therefore, in the case of passive seismic acquisition, it is necessary to select the best monitoring equipment for its success or failure. Hence, concerning sensors performance, this paper highlights the technological gap and motivates developing dedicated sensors for optimal solution at lower frequencies. Thus, the improved passive seismic recording helps in oil and gas industry to perform better fracture mapping and identify more appropriate stratigraphy at low frequencies.
\end{abstract}

\section{Introduction}

An increasing demand and supply of oil and gas require the industries to increase the survey for identifying reservoir field. Convention technique has been utilized for determining the petrophysical properties of reservoir but at a frequency range of $10-300 \mathrm{~Hz}$ [1]. Due to limited seismic bandwidth, sensors are unable to determine the complete information of a reservoir. Therefore passive seismic wavefield, that is, microtremors, is utilized as reservoir indicator to determine the petrophysical properties of rock at low frequency range of less than $10 \mathrm{~Hz}[2,3]$. Natural occurring seismic noise from the subsurface may act as a hydrocarbon-indicating signal. Spectral analysis using rock-physics mechanisms is performed for determining these signals below and above the hydrocarbon reservoir frequency range [4].

According to passive seismic technique, the key observation for identifying hydrocarbon reservoir is accurate sensing of seismic energy at lower frequency range of approximately $1-6 \mathrm{~Hz}[5]$.

For better stratigraphy, it is important to measure the spectral energy of a hydrocarbon signal both near and away from the well log. However, observed seismic energy for determining hydrocarbon reservoir may have wider range. On the contrary, geoscientists may consider a range of $1-6 \mathrm{~Hz}$ as a typical noise trough in the background spectrum which is the only frequency window for hydrocarbon-indicating signal $[6,7]$.

Furthermore, the research study of seismic energy at subsurface identifies some independent spectral attributes [8]. These attributes help in computing the spectral ratio between horizontal and vertical components of formation. Such ratio indicates the presence of hydrocarbon if the "Good" event of P-wave and S-wave arrives in the time domain (discussed in Section 4). Accurate arrival of source wave becomes a primary source and key indicator of low 


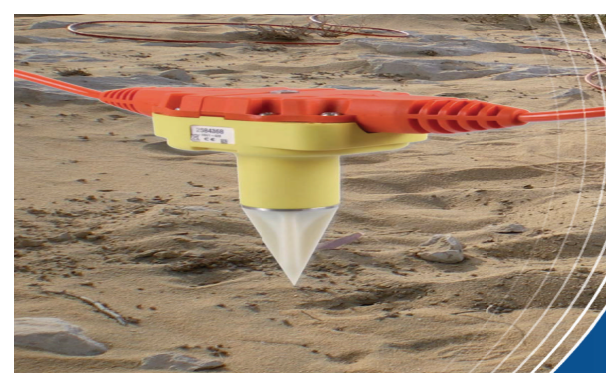

FIgURE 1: Accelerometer example: Digital Sensor Unit (DSU1) [18].

frequency microtremors in helping locating the presence of hydrocarbon reserves [1].

A time-reverse wave-propagation method is used for determining the "Good" event of source wave in depth domain near the well log. This is because well log data provides better characteristics of the rocks to distinguish the hydrocarbon reserves accurately $[1,2,21]$.

Based on the literatures and different levels of surveys, it is clear that current emerging and effective data analysis technique is passive seismic wavefield, that is, microtremors at low frequency for identifying hydrocarbon reserves accurately [22]. Since for real data analysis there must be a need for considering production noise in the measured data, based on this consideration, the data analysis using microtremors requires some careful assumptions such as the following:

(a) reservoir heterogeneity may cause misinterpretation of anomalies which is caused by noise;

(b) high noise (or high signal-to-noise ratio) during exploration may overwhelm seismic signals.

On the other hand, one inquiry likewise emerges amid investigation, whether microtremors can attain to the better correlation for both homogenous and heterogeneous kind of reservoir or not. The answer is conceivable to achievable by investigating the passive seismic data and its overview all the more obviously and precisely. It is a direct result of the way that passive seismic is the location of the earth encompassing seismic waves without the utilization of controlled source $[18,23]$. MEMS based accelerometers such as 1C (DSU1) or $3 \mathrm{C}$ versions (DSU3) are adept in order to sense various environments (e.g., transition zone or seabed), depicted in Figure 1. They can receive extensive attention because of their ability to give rich subsurface information at low cost and in environmentally friendly manner [24].

The use of passive seismic as a direct hydrocarbon indicator (DHI) has valuable promising advantages in reducing drilling risks, well positioning, and enhancing oil recovery [22]. The premise of the technique is the empirical observations of unique seismic energy anomalies over hydrocarbonbearing reservoirs. Existing studies attributed this phenomenon to the oscillation of hydrocarbon in pores driven by the omnipresent ambient seismic waves. Some mathematical models interpreting the phenomenon have been developed, for example, hydrocarbon microtremor analysis (HyMAS), Navier-Stokes model (NSM), and the linear harmonic oscillator model (LHOM) [21]. On the other hand, late studies uncovered results contradicting indisputably the correlation between the perceptions of tremor-like signs and the presence of hydrocarbon underneath $[24,29,41]$. Therefore, this overview proposed the thought of reservoir geology in relating watched microtremors-like signals to hydrocarbon vicinity. Accordingly, the principle critical concern of passive seismic studies is to get high resolution seismic information. This is because of the way that available sensors were not designed on the basis of passive seismic signal attributes mainly in terms of amplitude and bandwidth. Concerning sensors performance, this paper highlights the technological gap and motivates developing dedicated sensors for optimal solutions.

\section{Technical Infrastructure (Design and Modeling of Accelerometer)}

A fundamental test in simulating and designing MEMS device is the adjacent coupling between electrical, mechanical, optical, and diverse frameworks dynamic in all MEMS devices. Furthermore, a primary query concerning the coupling of the noise is identified that signifies processing with variant physical or dynamic components in any of the existing MEMS devices [9]. That is, does the vicinity of electronic noise, say Johnson (thermal) noise, influence mechanical (Brownian) noise, which can influence the little masses in MEMS devices, and the other way around? Correspondingly, thermal adsorption and desorption noise has mechanical behavior on a subatomic level but can incorporate electronic effects, when ions are incorporated [9].

Mechanical noise, for example, microphonics and vibrations, is regularly extrinsic. However, Brownian motion, a principal of intrinsic mechanical noise mechanism, exists, which may appear due to the dynamic unbalanced forces, happening due to the random impacts of atoms on a small ion particle or structure. Subsequently, it is likewise called "random walk" noise. Brownian movement turns out to be more critical as the span of a structure diminishes, for instance, the proof mass in MEMS accelerometer. Adsorption-desorption commotion is firmly identified with the Brownian movement because of random arrival and departure of distinct atoms and molecules on the surface of MEMS device. Table 1 implies the essential mechanical noise source for the device due to the Brownian motion of the gas particles encompassing the proof mass and the proof mass suspension or stays. In this manner, the aggregate noise equivalent acceleration (TNEA) $\mathrm{m} / \mathrm{s} 2$ [42] is

$$
\text { TNEA }=\sqrt{\frac{4 k_{B} T b}{m}} .
$$

Here, (1) clearly signifies that, to decrease the mechanical noise, the quality factor and proof mass must be incremented. Since the paper involves designing the MEMS based accelerometer, it is very much important to understand and identify the factor causing the mechanical noise [42]. It mainly occurred due the proof mass itself, which leads to the equivalent acceleration noise. Such noise is dominating and 
TABLE 1: A Comparative analysis on the characterization and noise analysis of MEMS device [9].

\begin{tabular}{lccc}
\hline Paper & Device or structure & Focus & Characterization \\
\hline Gabrielson [10] & $\begin{array}{c}\text { Accelerometers, pressure sensors, } \\
\text { capacitive microphones } \\
\text { Djuric [11] }\end{array}$ & $\begin{array}{c}\text { Accelerometers, infrared thermal } \\
\text { detector, microbeams }\end{array}$ & $\begin{array}{c}\text { Mechanical-thermal } \\
\text { Theory }\end{array}$ \\
\hline Djuric et al. [12] & Microcantilevers and microresonators & Several mechanisms & Theory \\
\hline $\begin{array}{l}\text { Greiner and Korvink } \\
\text { [13] }\end{array}$ & Micro bars & Several mechanisms & Theory and \\
Vig and Kim [14] & Resonputations \\
\hline Leland [15] & Gyroscopes & Several mechanisms & Theory \\
\hline
\end{tabular}

limiting the performance of MEMS devices, especially when operating under low acceleration conditions.

\subsection{Principle Design of MEMS Based Accelerometer. A} mechanical design of Microelectromechanical System (MEMS) based accelerometer consists of proof mass $m$, effective spring (with constant $k$ ), and damper (with coefficient $b$ ) affecting the dynamic motion of the mass produced by the air-structure interaction, as depicted in Figure 2.

The operation of the accelerometer can be modeled as a second-order mechanical system. When force is acted upon on the accelerometer, the mass develops a force which is given by D'Alembert's inertial force equation $F=m * a$. This force displaces the spring by a distance $x$. Hence the total force externally is balanced by the sum of internal forces given by [42]

$$
F_{\text {external }}=F_{\text {inertial }}+F_{\text {damping }}+F_{\text {spring }} \text {, }
$$

based on the mechanical design of MEM accelerometer vibration along the $x$ direction that showed the mechanical behavior of the system can be given by the differential equation [42]:

$$
m \frac{\partial^{2} x}{\partial t}+\beta \frac{\partial x}{\partial t}+k x=F_{\mathrm{ext}}=m a
$$

where $m$ is effective mass; $x$ is displacement; $\beta$ is damping coefficient; $k$ is spring stiffness; $F$ is force at the moving mass; and $A$ is acceleration of the moving mass.

Also, the transfer function in Laplace domain having displacement of $x$ can be represented as [42]

$$
\frac{x(s)}{a(s)}=\frac{1}{s^{2}+(b / m) s+k / m}
$$

or

$$
\frac{x(s)}{a(s)}=\frac{1}{s^{2}+(\omega n / Q) s+\omega_{n}^{2}},
$$

where $\omega_{n}=\sqrt{k / m}$, the resonant frequency, and $Q=\omega_{n} m / b$, the quality factor.

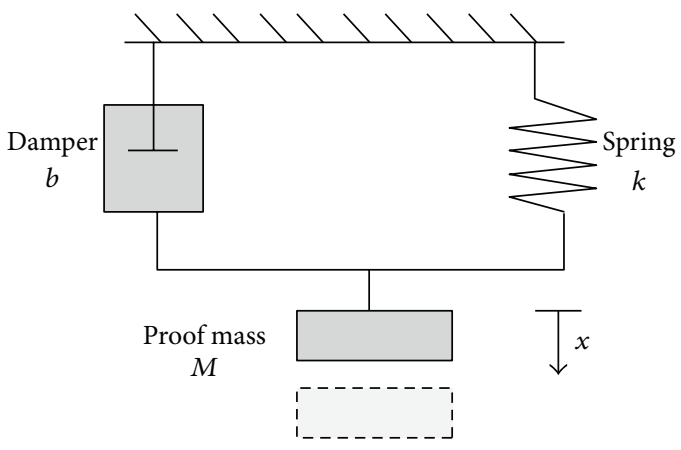

Figure 2: Mechanical design of MEMS accelerometer [9, 34, 42].

However, the device response time has been dictated principally by the natural frequency of the proof mass. Thusly, to accomplish critically damped acceleration, damping limitations must be necessary to take into consideration which permits getting the minimum amplitude distortion [34]. This means $Q=2 \sqrt{2}$. Therefore,

$$
\frac{b}{2 m \omega_{n}}=\frac{1}{\sqrt{2}} .
$$

But in order to characterize the damping, solving the dominator's equation by estimating $\Delta$ of the transfer function in (4) is needed:

$$
\begin{aligned}
s^{2}+\frac{b}{m} s+\frac{k}{m} & =0 \\
\Delta & =\left(\frac{b}{m}\right)^{2}-4 \frac{k}{m} .
\end{aligned}
$$

For $\Delta=0$, thus $b=2 \sqrt{\mathrm{km}}$, a damping coefficient.

Based on (6) and (7), three different cases must be considered in order to determine the variation in designing the bandwidth, such as the following:

(i) Underdamped system where $b<2 \sqrt{\mathrm{km}}$.

(ii) Critically damped system where $b=2 \sqrt{\mathrm{km}}$.

(iii) Overdamped system where $b>2 \sqrt{\mathrm{km}}$. 


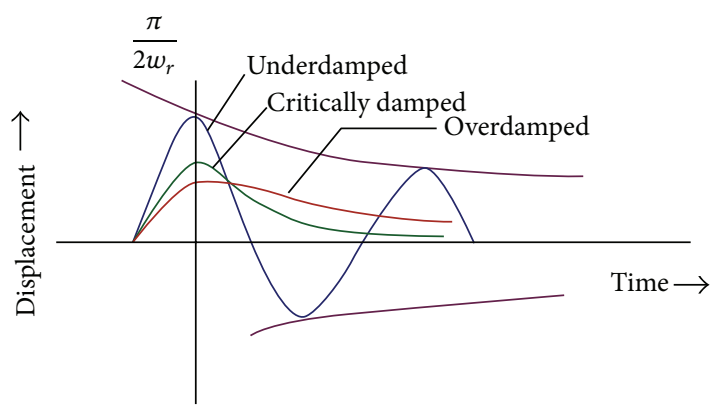

FIgURE 3: Step response of the accelerometer as a second-order mechanical system [42].

However, critical damping is essential for achieving maximum bandwidth. Since the absence of damping permitted very high levels of sensor resonant amplification it is furthermore recognizable that mass must be sufficiently huge to acquire the desired sensitivity with weak spring, as shown in Figure 3. In this manner, the mechanical resonance frequency of suspended mass is given by

$$
\omega_{n}=\sqrt{\frac{k}{m}}
$$

Such expansion and the analysis imply that in an open loop circuiting a high sensitivity of the device yields a small bandwidth, while in closed loop circuiting the resonance peak has been suppressed by the control circuit. It is also clear that the mechanical resonance of the sensor does not limit the bandwidth of the device, but it is limited by the transition frequency of the control circuit [44]. However, due to mechanical noise, Brownian motion noise comes into account, which has been utilized to indicate the unwanted signal as noise in the form of acceleration noise (see Table 1). Brownian noise has significant impact on both bulk and surface micromachined capacitive accelerometers. The measurement of the signal produced by the noise source and unsolicited signals is noise floor; therefore, it is clear that the real signal cannot be detectable if the measured signal has a value below this noise floor. Nonetheless, the variation in the frequency causes the change in the noise floor values, considering the Brownian noise having noise floor between 10 and $100 \mu \mathrm{g} / \mathrm{rtHz}$. Such noise generates the random force with Brownian motion of air molecules, which occurred because of the damping effect applied directly to the seismic mass. Therefore, the Power Spectral Density (PSD) of the Brownian noise force is depicted as [45]

$$
\bar{F}_{B}^{2}(f)=4 k_{B} T b,
$$

where $F_{B}$ is Brownian noise force; $k_{B}$ is Boltzmann constant; $T$ is absolute temperature; and $b$ is damping coefficient.

Here, it is clear that the damping coefficient $(b)$ is directly proportional to Brownian noise, such that the larger the value of damping coefficient is, the higher the noise will be or vice versa, as depicted in (9a). Therefore, reduction in the noise value requires anticipating the smaller value of the damping
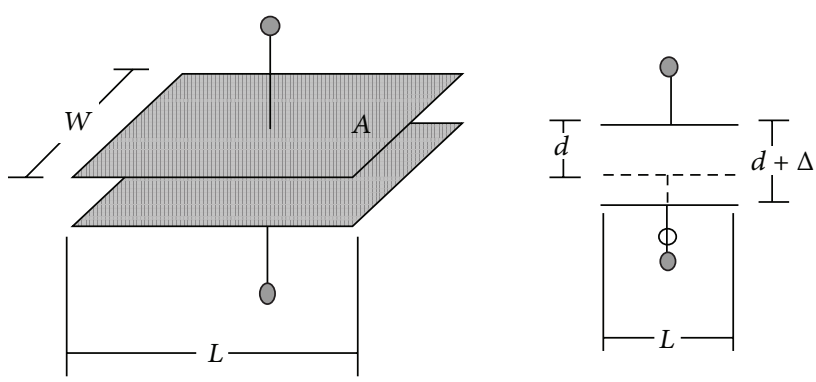

FIGURE 4: Capacitance change due to variation in plate separation [33].

coefficient and hence results in a smaller damping ratio $[44,45]$. Such ratio helps in modeling MEMS accelerometer running at underdamped condition having an oscillating mess in the designed accelerometer. Hence, to measure the accelerometer's noise performance, an acceleration-referred noise floor has been estimated by using Newton's law as [45]

$$
\bar{a}_{B}^{2}(f)=\frac{\bar{F}_{B}^{2}}{m^{2}}=\frac{\sqrt{4 k_{B} T b}}{9.8^{2} m^{2}} \mathrm{~g}^{2} / \mathrm{Hz} .
$$

Since the thermal-mechanical Brownian noise floor is within $10 \sim 100 \mu \mathrm{g} / \mathrm{rtHz}$, it might influence the processing and the device performance, where the noise is considered as process noise. Hence the minimum detectable acceleration is given by

$$
a_{\min }=\sqrt{\frac{8 \pi k_{B} T f_{n} B}{Q m}}
$$

or

$$
a_{\min }=\sqrt{\frac{4 k_{B} T b B}{m}} .
$$

However, from (5) and (8), the mathematical computation identifies that the bandwidth of an accelerometer sensing element is directly proportional to its sensitivity $(S)$; during the design it must be considered. Sensitivity of capacitive accelerometer is defined as the ratio of the difference of variation in the capacitance to the difference in variation in the displacement, which is depicted as

$$
S_{0}=\frac{A m \varepsilon}{k d^{2}}=\frac{C_{0} m}{k d}
$$

where $\varepsilon$ is the electric permittivity of air; $A$ is the overlap area of electrodes; and $d$ is the gap between the electrodes.

The most well-known utilization of capacitive detection for sensors depends on signals which are coupled to changes in the electrode partition, $d$. Let us consider a couple of electrodes with area $A$ and separation $d$, depicted in Figure 4, [33]. A physical signal causes the partition to increment by a small amount, $\Delta$. The capacitance changes

$$
\text { from } \frac{\varepsilon \varepsilon_{0}}{d} \text { to } \frac{\varepsilon \varepsilon_{0}}{d+\Delta} \text {. }
$$


Here, the correlation between the displacement and change in capacitance is not linear, but for a small change in the division, the capacitance can be estimated by utilizing a Taylor series expansion. Generally, any function, $F(d)$, can be approximated in the neighborhood of some nominal valued $d(0)$ as follows [33]:

$$
\begin{aligned}
F\left(d_{0}+\Delta\right)= & F\left(d_{0}\right)+\Delta \frac{\partial F\left(d_{0}\right)}{\partial d}+\frac{\Delta^{2}}{2} \frac{\partial^{2} F\left(d_{0}\right)}{\partial d^{2}} \\
& +\cdots .
\end{aligned}
$$

Based on the above expression, this expansion can be implemented as

$$
C \approx \frac{\varepsilon \varepsilon_{0} A}{d}\left(1-\frac{\Delta}{d}+\frac{\Delta}{d^{2}}\right),
$$

where $\Delta=d-d_{0}$.

So, for $\Delta \ll d$, the change in capacitance has linear relationship with respect to the displacement. The nonlinearity of the function has been considered as a correction term of order $\Delta^{2} / d^{2}$, such that nonconsideration of such error makes the signal remain nearly linear [33]. This creates a new relationship such that the sum of the forces on the mass is equal to the acceleration of the mass (see Figure 2) such that

$$
k(X-x)+b \frac{d(X-x)}{d t}=m \frac{d^{2} x}{d t^{2}},
$$

where $X$ is position of the frame in Figure 2; $x$ is position of the mass in Figure 2.

Therefore, the maximum detectable acceleration having total gap between the electrodes, $d_{\max }$, is given by

$$
a_{\max }=k \frac{d_{\max }}{m} .
$$

Additionally, the above equations signify that spring constant " $k$ " affects directly the resonant frequency, bandwidth, sensitivity, and furthermore the pull-in voltage. Basically, the spring constant is directly proportional to the beam characteristics, such as the length $(L)$, the thickness $(t)$, the width $(W)$, and the elasticity of the material coefficient (Young's Modulus $(E)$ ) [44]. Such variation in the spring constant in a beam occurs due the tensile and compressive stresses, which is considered negligible during implementation, and therefore the following equation can be defined for further application:

$$
k=\frac{W t^{3}}{L^{3}} E,
$$

where $E$ is Young's Modulus of the material utilized having unit of gigapascals, that is, GPa.

Since, volume of proof mass is $V=L_{m} T_{m} W_{m}$ and is homogeneously parallelepiped with rectangular area $(A)$, the volume must be estimated from the volumic mass density $\rho$ as

$$
\begin{aligned}
\rho & =\frac{m}{V} \Longrightarrow \\
V & =\frac{m}{\rho} .
\end{aligned}
$$

Therefore, the computation of the thickness $\left(T_{m}\right)$ of the device is defined as

$$
\begin{aligned}
V & =L_{m} W_{m} T_{m}=A \cdot T_{m} \Longrightarrow \\
T_{m} & =\frac{V}{A} .
\end{aligned}
$$

Furthermore, based on the above mathematical modeling, the geometry of the design accelerometer and its proof mass are defined. Such modeling of the proof mass of the accelerometer clearly depends on the various dimensions of the sensing elements depicted in Figure 5.

The parameters utilized in Figure 5, such as width, thickness, and length of the proof mass and anchor, depend upon the selection of the type of the model which is illustrated in Table 16 (Appendix). Furthermore, the sensitivity of the accelerometer is dependent on the size of proof mass, spring constant, and resonance frequency, graph in Figure 6, illustrating the phenomena that proof mass and resonance frequency are inversely proportional to each other; with increase in proof mass the resonance frequency decreases and vice versa.

High resolution acquisition for microtremor signals is a crucial market concern for passive seismic hydrocarbon exploration studies (Figure 7). The technological lag between the application requirements and performance offered by available and emerging accelerometers motivates the development of dedicated sensing technology, depicted in Table 2 [16-20].

2.2. Accelerometers Performance Overview. MEMS devices for seismic applications have previously been designed using piezoresistive [49], capacitive [10], and piezoelectric typed sensors [50]. Electron tunneling is also a very promising sensing mechanism due to its high sensitivity to low vibrations [51]. The performance of accelerometers can be characterized based on demonstrated operational specifications including the following.

(i) Acceleration Range. Recording unnecessary high amplitude signals adversely affects sensor sensitivity and consequently the resolution [52]. It is necessary to know the acceleration range that is defined as the maximum acceleration input that can be measured by the accelerometer in $\mathrm{g}$ (acceleration due to gravity) $\left(\approx 10 \mathrm{~ms}^{-2}\right)$. As a result, an ideal accelerometer should be able to capture maximum vibrations of geophysical interest.

(ii) Bandwidth. It refers to the frequency range of input acceleration that the sensor can perform with minimum distortion. An ideal accelerometer requires minimum bandwidth to reduce undesired noise [52] and should have maximum bandwidth that is sufficient to accommodate all signals of interest.

(iii) Noise Floor. The noise collectively, generated at the sensor output when no acceleration is present, is referred to as sensor noise floor. It is a composite of three noise sources: the thermomechanical noise (i.e., Brownian noise) $[49,53]$, 
TABLE 2: Comparison of existing MEMS accelerometers [16-20].

\begin{tabular}{lcccc}
\hline Sensor & Supplier & Bandwidth $(\mathrm{Hz})$ & Full scale $(\mathrm{mg})$ & Noise density $(\mathrm{ng} / \sqrt{\mathrm{Hz}})$ \\
\hline Trillium [20] & Nanometrics & $0.03-50$ & - & - \\
GAC [17] & WesternGeco & $3-200$ & 108 & 15 \\
DSU1 [18] & Sercel & $0-800$ & 500 & $40(>10 \mathrm{~Hz})$ \\
HP sensor [19] & HP & $1-200$ & 80 & 10 \\
\hline
\end{tabular}

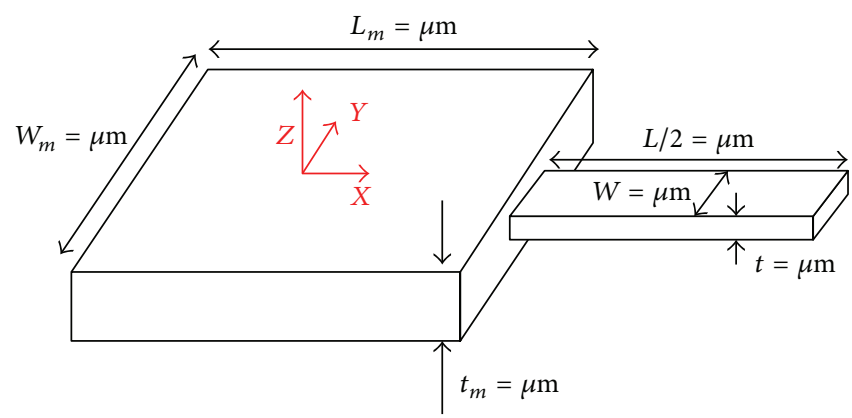

Figure 5: Sensing element dimensions.

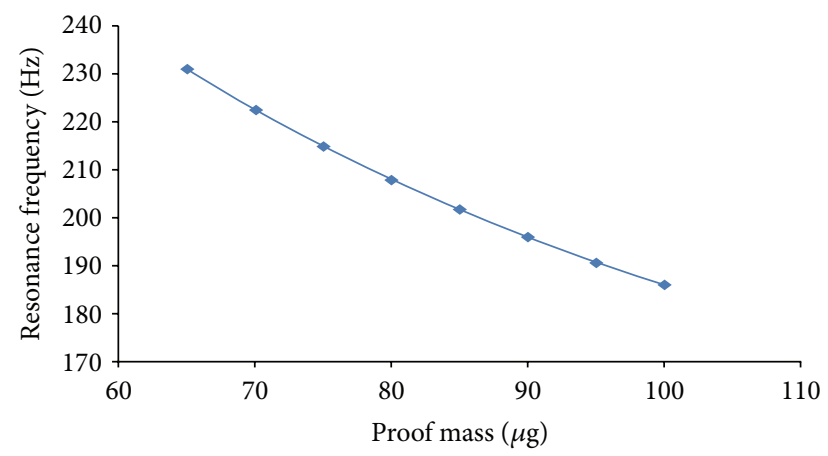

FIGURE 6: Resonance frequency versus proof mass.

the thermoelectrical noise (i.e., Johnson noise), and the $1 / f$ noise (Hooge's noise) [54]. The first one is due to the random motion induced by thermal energy of gaseous molecules surrounding the proof mass [10]. The thermoelectrical noise is attributed to the random electron motion in the wires induced by ambient thermal energy. Hooge's noise is empirical noise and is function of the frequency. For simplicity, the total noise floor $a_{\mathrm{n}}$ can be expressed in terms of mechanical noise $\left(a_{\mathrm{nm}}\right)$ and electrical noise $\left(a_{\mathrm{ne}}\right)$ as displayed in

$$
a_{n}=\sqrt{a_{\mathrm{nm}}^{2}+a_{\mathrm{ne}}^{2}}
$$

The noise floor is desirable to be as minimal as possible, but an acceptable level can be determined by the required resolution. To evaluate the need for dedicated sensors for hydrocarbon microtremor analysis studies, available accelerometers have been reviewed. Eventually, matching analysis between sensing requirements and performance metrics is performed to scope down design possibilities and guide promising directions. Based on the employed sensing principle, the discussion on performance metrics is

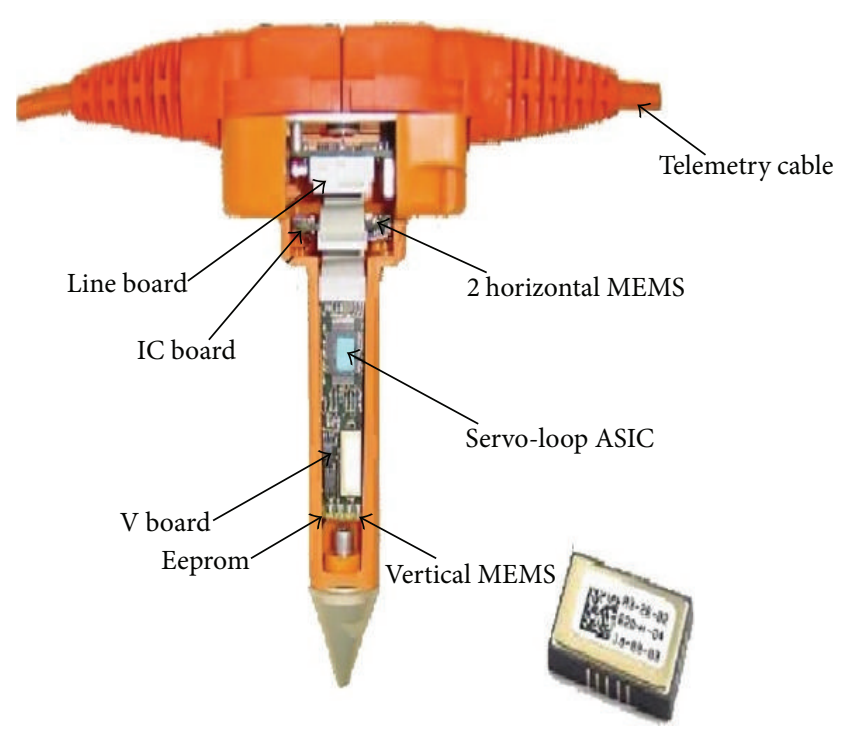

FIgURE 7: Three-axis (3-component) seismic sensor unit [16]: example of accelerometer used in seismic application.

categorized into piezoresistive, capacitive, piezoelectric, and tunneling accelerometers.

2.2.1. Piezoresistive. Piezoresistive accelerometers exploit the piezoresistive effects of materials, typically polysilicon, to measure the acceleration $[50,51]$. The piezoresistive elements are embodied in structure in such a way to be subjected to torsion when acceleration is applied [50]. The structure can typically be a suspended beam with one end attached to a proof mass [54]. The proof mass movement imposes stress changes on the piezoresistive element thus changing its resistance. Figure 8 shows a typical example of this type of accelerometer. In this example, the proof mass movement 


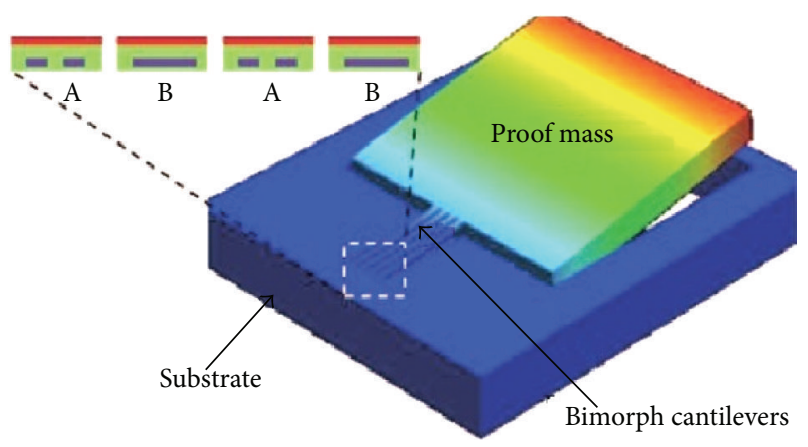

FIgURE 8: Piezoresistive accelerometer showing the embodied piezoresistors (A, B) within the cantilever [43].

implies stress changes along the embedded piezoresistive elements (polyresistors) in the bimorph cantilever. A Wheatstone bridge-like circuitry is used to measure resistance change and deduce acceleration.

For more than three decades, piezoresistive accelerometers (e.g., [49, 52, 53, 55-64]) have shown progressive improvements making them a viable option for various applications including microgravity and low frequency applications $[59,63]$.

The demonstrated performance of these devices is shown as in Figure 8.

(i) Acceleration Range. Piezoresistive accelerometers have been designed to work in ranges as small as $1 \mathrm{~g}$ [55] or as large as $250 \mathrm{~g}$ [61]. In average, they work within $10-50 \mathrm{~g}$ [ 49 , $52,53,56-60,62-64]$. This operation range is two orders of magnitude larger than desired operation range ( $4 \mathrm{ng}-80 \mathrm{mg}$ ).

(ii) Bandwidth. Piezoresistive accelerometer designs [53, 55, 58-63] statistically tend to have a median bandwidth of $1 \mathrm{KHz}$. The upper measurement limit typically varies between $100 \mathrm{~Hz}$ and $2 \mathrm{KHz}$, whereas the lower limit is conventionally nonzero $(5-100 \mathrm{~Hz})[46,55,59,63-65]$, except for the case of employing nanowires [66] that are able to respond to $0 \mathrm{~Hz}$ acceleration (static acceleration).

(iii) Noise Floor. The noise floor is generally in range of $100-$ $500 \mu \mathrm{g} / \sqrt{\mathrm{Hz}}[55,56,59,63,64]$.

Table 3 summarizes the performance characteristics of piezoresistive accelerometers. They are advantageously simple in structure, fabrication, and their read-out circuitry [54]. On the other hand, the demonstrated performance does show capability in neither operating in sub-g domain nor achieving bandwidth $<50 \mathrm{~Hz}$ or a noise floor below $5 \mathrm{ng} / \sqrt{\mathrm{Hz}}$. Additionally, piezoresistive accelerometers can be seen to have intrinsic temperature sensitivity and measurement drifts [62]. These limitations could reduce their suitability for intended hydrocarbon microtremor measurements of current concern.

2.2.2. Capacitive. Capacitive accelerometers are dominant accelerometers in market. The high sensitivity, good noise performance, and low temperature sensitivity are among their features [54]. In principle, capacitive types exploit the change of capacitance between plates on free moving
TABLE 3: Piezoresistive accelerometers performance range.

\begin{tabular}{lccccc}
\hline Acceleration range $(\mathrm{g})$ & \multicolumn{2}{c}{ Bandwidth $(\mathrm{Hz})$} & \multicolumn{2}{l}{ Noise density $(\mathrm{g} / \sqrt{\mathrm{Hz}})$} \\
\hline Small & $\sim 1 \mathrm{~g}$ & Lower limit & $5-100$ & Low & $100 \mu$ \\
Medium & $10-50 \mathrm{~g}$ & BW & $\sim 1 \mathrm{k}$ & & \\
\hline Large & $\sim 250 \mathrm{~g}$ & Upper limit & $100-2 \mathrm{k}$ High & $500 \mu$ \\
\hline
\end{tabular}

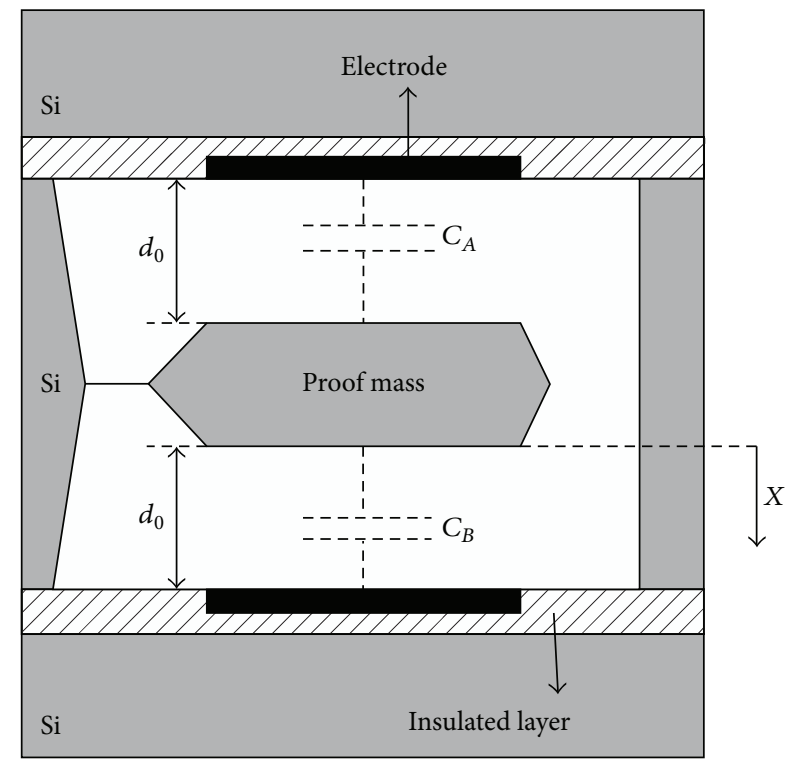

FigurE 9: Capacitive sensing principle [46].

and fixed microstructures when acceleration is applied [50]. Figure 9 shows a simple cantilever structure of capacitive type accelerometer. The structure consists of proof mass suspended via cantilever while the movement is sensed via electrodes.

For quantitative analysis, the performance of capacitive accelerometers in $[19,65-112]$ is presented as follows.

(i) Acceleration Range. Depending on order of magnitude, capacitive accelerometers can be observed to operate in four different ranges: (i) sub-g ( $\mu$ g-mg) range [18, 96, 103], (ii) 1$10 \mathrm{~g}$ range $[65-68,76,77,80,84-89,92,95-97,100-102,105]$, (iii) $10-100$ g range $[69,72-74,93,99,104-106]$, and (iv) above $1000 \mathrm{~g}[90,91]$.

(ii) Bandwidth. The bandwidth of capacitive accelerometers typically starts at DC $(0 \mathrm{~Hz})[65-68,86,104,105]$; in some cases it can begin at nonzero frequencies $[19,79,92]$. Commonly, their bandwidth falls in range of $100-1000 \mathrm{~Hz}$, but it can typically vary in less than $100 \mathrm{~Hz}$ [69] and above $1000 \mathrm{~Hz}[85,110]$.

(iii) Noise Floor. The noise performance of capacitive accelerometers varies from $4 \mathrm{ng} / \sqrt{\mathrm{Hz}}$ [92] up to $400 \mathrm{mg} / \sqrt{\mathrm{Hz}}$ [102]. More than $60 \%$ of capacitive accelerometers have noise floor within $\mu \mathrm{g} / \sqrt{\mathrm{Hz}}$ (i.e., between 0.1 and $100 \mu \mathrm{g} / \sqrt{\mathrm{Hz}}$ ).

Capacitive accelerometers offer wide performance capabilities as shown in Table 4. The wide capability variation enables their successful utilization in different industrial 


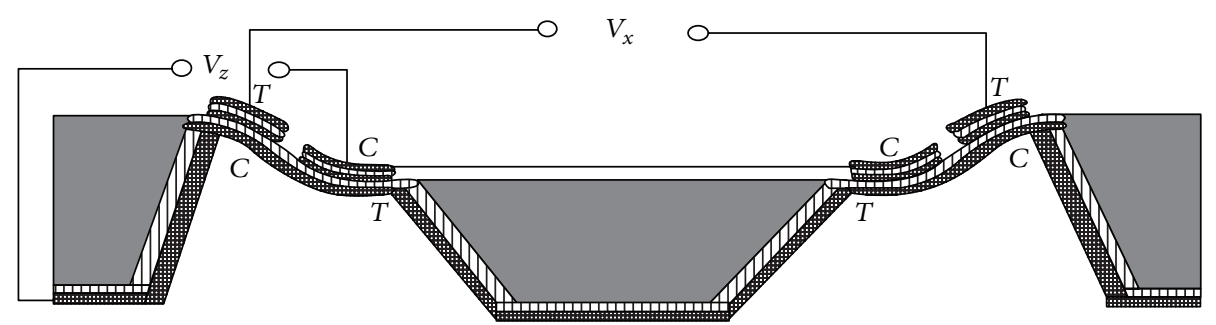

FIGURE 10: Accelerometer structures using piezoelectric sensing [47].

TABLE 4: Capacitive accelerometers performance range.

\begin{tabular}{lccccc}
\hline \multicolumn{2}{l}{ Acceleration range $(\mathrm{g})$} & \multicolumn{3}{c}{ Bandwidth $(\mathrm{Hz})$} & \multicolumn{2}{c}{ Noise density $(\mathrm{g} / \sqrt{\mathrm{Hz}})$} \\
\hline Small & $<1 \mathrm{mg}$ & Small & $<100$ & Small & $4 \mathrm{n}-1 \mu$ \\
\hline Medium & $1-10 \mathrm{~g}$ & Medium & $100-1 \mathrm{k}$ & Medium & $1 \mu-1 \mathrm{~m}$ \\
\hline Large & $10-100 \mathrm{~g}$ & Large & $>1 \mathrm{k}$ & Large & $>1 \mathrm{~m}$ \\
Very large & $>1000$ & & & & \\
\hline
\end{tabular}

domains including biomedical domain, navigation, space microgravity, military, and also seismology [19, 65-112]. Remarkably the authors in [92] demonstrated noise performance approaching the required noise floor of HyMAS application. However, the device resolution is lower than the desired value because of the wide bandwidth. Therefore, a gap on achieving the required noise density and bandwidth has still not been met.

The simple structure, low drift, and low temperature sensitivity of capacitive accelerometers along with demonstrated performance make them suitable design option for seismic applications $[46,112]$.

2.2.3. Piezoelectric. Piezoelectric accelerometers employ materials with piezoelectric effects to indirectly measure acceleration via amount of deposited electric charges when stress is induced [50]. They are generally featured by low power consumption and temperature stability and have been used in several applications including medical and machine vibration monitoring [47, 62, 113-117].

A typical accelerometer utilizing piezoelectric principle is illustrated in Figure 10, in which the movement of the proof mass imposes deformation on the piezoelectric elements on the supporting bimorph beam. The charge deposition along the sensing element induces electrical potential $\left(V_{x}\right.$ and $\left.V_{z}\right)$ whose magnitude indicates the acceleration applied.

The performance of accelerometers is discussed as follows.

(i) Acceleration Range. Piezoelectric accelerometers demonstrate a measurement range around 20-25 g [116], but they do not suit sub-g operation range. Additionally, the inherited hysteresis effect reduces the measurement precision that is essentially required for geophysical seismic measurement.

(ii) Bandwidth. Piezoelectric accelerometers are normally used in dynamic operation mode, which can result in leakage
TABLE 5: Piezoelectric accelerometers performance range.

\begin{tabular}{lccccc}
\hline Acceleration range $(\mathrm{g})$ & \multicolumn{2}{c}{ Bandwidth $(\mathrm{Hz})$} & \multicolumn{2}{c}{ Noise density $(\mathrm{g} / \sqrt{\mathrm{Hz}})$} \\
\hline Low & 20 & $\begin{array}{c}\text { Small } \\
\text { Medium }\end{array}$ & $\begin{array}{c}100-60 \\
\text { 10 }\end{array}$ & Low & $10 \mathrm{n}-700 \mathrm{n}$ \\
\hline High & 25 & Large & $3.7 \mathrm{k}-35 \mathrm{k}$ & High & 0.1 \\
\hline
\end{tabular}

and creep issues [54]. The dynamic range is typically within $0.1 \mathrm{kHz}-10 \mathrm{kHz}[62,113-116]$ but can be as high as $3.7 \mathrm{kHz}-$ $35 \mathrm{kHz}$ [114] or as low as $1 \mathrm{~Hz}-60 \mathrm{~Hz}$ [47].

(iii) Noise Floor. It falls within the range of $10 \mathrm{ng}$ to $700 \mathrm{ng}$ in designs $[47,116,117]$, whereas the early designs suffer from large noise floor reaching up to $0.1 \mathrm{~g}$ [113].

Table 5 summarizes the performance characteristics of piezoelectric accelerometers. From presented literature, they show substantial performance improvement in the acceleration range, bandwidth, and noise level, over the last decades. This could make them viable choice of design for passive seismic. However, the inherited creep and tendency for dynamic measurements can reduce their suitability for passive seismic geophysical applications.

2.2.4. Electron Tunneling. Tunneling accelerometers exploit changes of current tunneling through insulating medium with change of separating displacement [48, 118-121]. Figure 11 shows an accelerometer schematic using the electron tunneling principle. It is seen that the tunneling tip is just beneath a suspended proof mass. A deflection electrode and proof mass electrodes provide electrostatic force required to control the tunneling current.

Electron tunneling is very promising in seismic application field because of performance high sensitivity, small size, and light weight compared to piezoresistive or capacitive types. The demonstrated measurement capabilities are stated as follows.

(i) Acceleration Range. During the last two decades $30 \mathrm{~g}$ range was typically reported [119, 120]. Later, $1 \mathrm{mg}$ range was maximally reported $[48,121]$, which proved its sensor capability to work in seismic operation.

(ii) Bandwidth. Frequently, accelerometers are designed to work minimally at $1 \mathrm{kHz}$ bandwidth [47, 113-122]. This range can reach up to $6 \mathrm{kHz}$ [123-125]. Notably, tunneling accelerometers have a limit for the minimum detectable 
TABLE 6: Tunneling accelerometers performance range.

\begin{tabular}{lccccc}
\hline Acceleration range $(\mathrm{g})$ & \multicolumn{2}{c}{ Bandwidth $(\mathrm{Hz})$} & \multicolumn{2}{c}{ Noise density $(\mathrm{g} / \sqrt{\mathrm{Hz}})$} \\
\hline Low & 20 & $\begin{array}{c}\text { Small } \\
\text { Medium }\end{array}$ & $\begin{array}{c}1-60 \\
100-10 \mathrm{k}\end{array}$ & Low & $10 \mathrm{n}-700 \mathrm{n}$ \\
\hline High & 25 & Large & $3.7 \mathrm{k}-35 \mathrm{k}$ & High & 0.1 \\
\hline
\end{tabular}

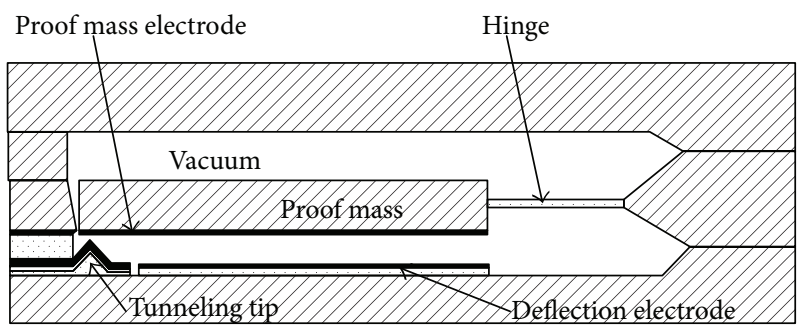

Figure 11: Cross sectional view of tunneling accelerometer with cantilever structure [48].

frequency. This limit is typically in range of $5-200 \mathrm{~Hz}[48,119$, 121].

(iii) Noise Floor. In early tunneling devices, the noise floor varied over a range from $1 \mu \mathrm{g} / \sqrt{\mathrm{Hz}}$ to $4 \mathrm{mg} / \sqrt{\mathrm{Hz}}[119,120$, 122]. As technology advances, a noise floor at nanometer range $(15-250 \mathrm{ng} / \sqrt{\mathrm{Hz}})$ has been achieved $[48,121]$. Table 6 summarizes the performance characteristics of tunneling accelerometers in literature. Tunneling accelerometers show seismic grade performance with some exception on the wide bandwidth of $1 \mathrm{kHz}$. Therefore, further filtration process is required for narrow bandwidth signals.

2.2.5. Resistive Accelerometers. Resistive accelerometers recognize the change of resistance of a metal strain gauge clung to a cantilever beam. Accelerating prompts twisting of the cantilever beam and hence causes variation in the resistance of the strain gauge. In case of a metal foil, the geometric effect is identified significantly dominating the piezoelectric effect [50]. The model of a Wheatstone bridge circuit configured four strain gauges which provide a voltage signal and work for DC estimation.

2.2.6. Optical Accelerometers. An optical accelerometer distinguishes the change of optical characteristics in an optical fiber. The Fiber Bragg Grinding (FBG) is one of the most standard and popular techniques for fiber optical estimation [126, 127]. In this technique, Bragg gratings are the interference filter composed of optical fibers. The characteristic of FBG accelerometers defines that the appraisals reflect just a narrow spectral component of actuated light. Acceleration prompts a distortion of an optical fiber connected to a suspended beam causing a change in the reflection characteristic of the Bragg gratings. This change can be distinguished by contrasting the spectral component of the reflected beam with the impelled light. Hence, FBG accelerometer is used to perform optical signal analysis with DC estimations.
TABLE 7: Sensors performance summary.

\begin{tabular}{lccc}
\hline Type & $\begin{array}{c}\text { Bandwidth } \\
(\mathrm{Hz})\end{array}$ & $\begin{array}{c}\text { Acceleration } \\
(\mathrm{g})\end{array}$ & $\begin{array}{c}\text { Noise density } \\
(\mathrm{g} / \sqrt{\mathrm{Hz}})\end{array}$ \\
\hline Capacitive & $0-30$ & $22 \mu-20 \mathrm{k}$ & $4 \mathrm{n}-357 \mathrm{~m}$ \\
Piezoresistive & $0-35$ & $1-250$ & $100 \mu-500 \mathrm{~m}$ \\
Piezoelectric & $1-60$ & $7-25$ & $10 \mathrm{~m}-110 \mathrm{~m}$ \\
Tunneling & $5-1 \mathrm{k}$ & $1 \mathrm{~m}-30$ & $15 \mathrm{n}-4 \mathrm{~m}$ \\
\hline
\end{tabular}

2.2.7. Thermal Accelerometers. Thermal accelerometer has been driven based on mass displacement and does not found a popularity among others in terms of manufacturer selling [127]. Therefore, the suited alternative solution of this issue is thermal accelerometer without mass displacement [127]. It consists of a heater and thermocouples situated around the radiator in a hermetic chamber. On applying acceleration to the accelerometer, hot air in the chamber moves that leads to generating an asymmetric temperature profile. Such asymmetric profile can be identified by the thermocouples around the radiator. This process is called transduction principle which produces a voltage signal using these accelerometers and work for DC estimation [128].

2.3. Analysis and Design Challenges. For comparative analysis, previously mentioned works have been summarized in Table $7[6,7,34,43,46,62-64]$. The first column shows the sensing type of accelerometers. The smallest operating bandwidth, the upper limits of acceleration range, and measured noise floor levels are listed in columns 2-4, respectively. The data summarized in Table 7 indicates the superiority of capacitive sensors to meet passive seismic sensing requirements. According to Section 2.2, signals required in passive seismic survey have maximum acceleration of $<80 \mathrm{mg}$ and bandwidth of $1-30 \mathrm{~Hz}$ with $<1 \mathrm{ng} / \sqrt{\mathrm{Hz}}$ noise spectral density.

The key in designing high resolution capacitive accelerometer is to reduce the device's noise floor and increase its sensitivity as demonstrated in $[19,88,92,93,104,122,123]$. The total noise floor comes from mechanical and electrical elements of the sensor.

(i) Design Overview. The Brownian noise is principally proportional to the square root of damping factor $(b)$ and inversely proportional to the proof mass $(m)$ as in (17), where $k_{B}$ and $T$ are Boltzmann's constant $\left(1.38 \times 10^{-23} \mathrm{~J} / \mathrm{K}\right)$ and the temperature in Kelvin:

$$
a_{\mathrm{nm}}=\frac{\sqrt{4 k_{B} T b}}{9.8 m} .
$$

Therefore, ultralow noise accelerometers have large proof mass and low gas damping in the mass-spring accelerometer system $[19,92]$. The mechanical noise can be defined as a function of the temperature, damping coefficient, and mass. While the temperature can be set to $20^{\circ} \mathrm{C}$ or $293.15^{\circ} \mathrm{K}$, the damping coefficient and mass are dependent on the geometry of the structure. 


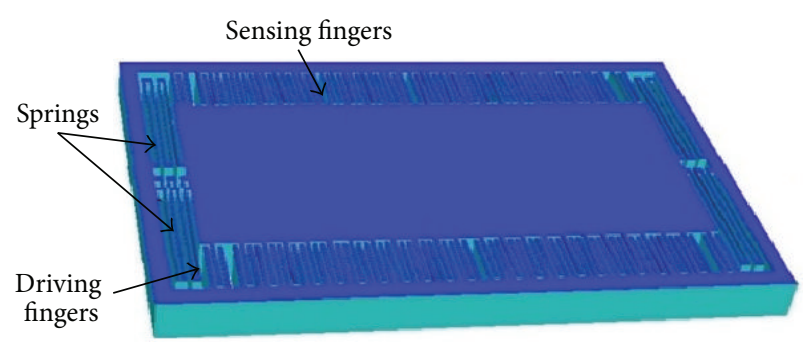

(a)

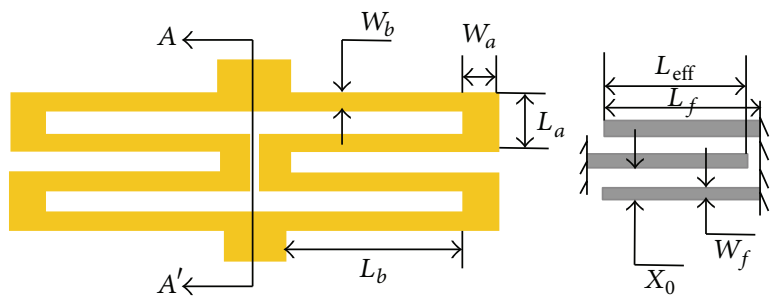

(b)

FIGURE 12: Structure of a lateral capacitive accelerometer: (a) isometric device view; (b) spring parameters $\left(W_{b}, W_{a}, L_{a}, L_{b}\right)$ and fingers parameters $\left(X_{0}, W_{f}, L_{f}, L_{\text {eff }}\right)[124]$.

In the electrical domain, the noise can be minimized by reducing the operating bandwidth. Additionally a closedloop feedback electronic circuit is required to compensate the nonlinear response of the mechanical system and to shorten the bandwidth of the device to $30 \mathrm{~Hz}$. To minimize the noise effect from amplifier, the rate of capacitance change with acceleration needs to be maximized [19]. Maximizing the sensitivity requires minimizing sensing gap and lowering the natural resonant frequency $[19,92,129]$.

As previously discussed, the minimum detectable acceleration should be $=80 / 2^{24}=4.7 \mathrm{ng}$. This implies that the maximum mechanical noise $a_{m}$ should be less than $0.86 \mathrm{~g} / \sqrt{\mathrm{Hz}}$ according to

$$
a_{m}=\frac{a_{\min }}{\sqrt{\mathrm{BW}}}=\frac{4.7 \mathrm{ng}}{\sqrt{30}}=0.86 \mathrm{~g} / \sqrt{\mathrm{Hz}} .
$$

In order to size the design challenges of ultralow noise floor, a case study on accelerometer design with conventional comb structure is considered. The structure as shown in Figure 12 comprises a fixed rectangular frame with fingers and a moving proof mass fixed on the frame by spring-like shape at both ends and surrounded by fingers at its both sides.

Accelerometers noise performance is generally determined by the damping coefficient and proof mass size as suggested by (5). The dominant damping mechanism in this structure is due to the squeeze-film effect [125]. Therefore, the damping coefficient $b$ can be written in

$$
b=7.2 N \mu t\left(\frac{l_{\mathrm{eff}}}{x_{0}}\right)^{3}
$$

whereby $N$ is the number of comb fingers; $t$ is the proof mass thickness; $\mu$ is the viscosity of the air under atmospheric pressure $20^{\circ} \mathrm{C}=1.54 \times 10^{-6} \mathrm{~kg} / \mathrm{m} / \mathrm{s}$; and $l_{\text {eff }}$ is the engaged length of the comb fingers.

Moreover, the mass $m$ can be expressed in (20), where $m$ defines the mass of the proof mass, $\rho$ is the silicon density $=$ $2330 \mathrm{~kg} / \mathrm{m}^{3}, l_{f}$ is the length of comb fingers, $W_{f}$ is the width of comb fingers, and $A$ is the area of the proof mass:

$$
m=t \rho\left(A+N l_{f} W_{f}\right) .
$$

As a result, the mechanical noise $a_{\mathrm{nm}}$ can be expressed by substituting (19) and (20) in (17) to obtain

$$
a_{\mathrm{nm}}=\frac{\sqrt{4 k_{B} T\left[7.2 N \mu t\left(l_{\mathrm{eff}} / x_{0}\right)^{3}\right]}}{9.8\left[t \rho\left(A+N l_{f} W_{f}\right)\right]} .
$$

As depicted in Figure 12(a), the proof mass parameters $A$ and $t$ typically have large values compared to fingers dimensions $L_{\text {eff }}, L_{f}, W_{f}$, and $X_{0}$ [124]. As a result, the proof mass is effectively increased by enlarging parameters $A$ and $t$.

The realization of sub-ng/ $\sqrt{\mathrm{Hz}}$ of noise spectral density through mass maximization has a positive impact on device sensitivity. This can be explained by the proportional relationship between sensitivity and mass as displayed in

$$
S=\frac{V_{s}}{a_{\text {in }}}=\frac{4 C_{s}}{2 C_{s}+C_{p}} \cdot \frac{V_{\mathrm{m}}}{x_{0}} \cdot \frac{m}{k}
$$

whereby $S$ is the sensitivity $(\mathrm{V} / \mathrm{g}) ; C_{s}$ is the sensing capacitance; $C_{p}$ is the parasitic capacitance; $V_{\mathrm{m}}$ is maximum output voltage $(\mathrm{V}) ; a_{\text {in }}$ is maximum input acceleration $(\mathrm{g})$; and $k$ is the spring constant $(\mathrm{N} / \mathrm{m})$.

The maximization of sensitivity is an important design goal. This is achievable by maximizing the proof mass and minimizing the spring constant as suggested by (22). However, the resonant frequency has to be considered. Equations (23) and (24) describe the structural dependencies of the spring constant $k$ and the device resonant frequency $f$, respectively, as follows:

$$
\begin{aligned}
& k=2 \frac{1}{(n-1)^{3}} \cdot E\left(\frac{W_{b}}{2 L_{b}}\right)^{3} t \\
& f=\frac{1}{2 \pi} \cdot \sqrt{\frac{k}{m}},
\end{aligned}
$$

where $n$ is the number of mechanical spring turns; $W_{b}$ is the width of single turn spring; $L_{b}$ is the length of single turn spring; and $E$ is Young's Modulus of silicon $=1.54 \times$ $10^{-6} \mathrm{~kg} / \mathrm{m} / \mathrm{s}$.

2.3.1. Summarized Analysis of the Type of Accelerometers. For initial analysis, (18)-(23) have been solved yielding to the 
TABLE 8: Initial design parameters and values.

\begin{tabular}{lccc}
\hline Parameter & Value & Parameter & Value \\
\hline$l_{\text {eff }}$ & $80 \mu \mathrm{m}$ & $n$ & 8 \\
$l_{f}$ & $85 \mu \mathrm{m}$ & $x_{0}$ & $8.3 \mu \mathrm{m}$ \\
$W_{f}$ & $4.8 \mu \mathrm{m}$ & $t$ & $33.18 \mu \mathrm{m}$ \\
$N$ & 200 & $l_{b}$ & $2 \mathrm{~mm}$ \\
$A$ & $5 \mathrm{~mm} \times 5 \mathrm{~mm}$ & $W_{b}$ & $75 \mu \mathrm{m}$ \\
$m$ & $2 \mu \mathrm{g}$ & $a_{\mathrm{nm}}$ & $0.85 \mathrm{ng} / \mathrm{rtHz}$ \\
$f$ & $46 \mathrm{~Hz}$ & $S$ & 0.26 \\
\hline
\end{tabular}

values as listed in Table 8 . The table shows the parameters and the corresponding values for the design in rows 2-6. The resulting device performance (noise, resonant frequency, and sensitivity) is shown in the last two rows. The table shows that a $5 \mathrm{~mm} \times 5 \mathrm{~mm}$ proof mass area was required. Even though the sensitivity $(0.26 \mathrm{~V} / \mathrm{g})$ is lower than stateof-the-art value, this device is considered large structure for conventional CMOS technology. To improve the sensitivity, further enlargement for the proof mass is required. This shows the major challenge of the design.

Therefore, achieving the noise spectral density of less than $1 \mathrm{ng} / \sqrt{\mathrm{Hz}}$ on a conventional capacitive structure is challenging. As a result, a novel structure and design optimization is expected to meet the stringent resolution level requirements.

2.3.2. Conclusion on the Analysis. The excessive demands for hydrocarbon have pushed the exploration technology to the era of passive seismic monitoring. The technique is economically promising and environmentally friendly but facing several challenges among which is the high resolution acquisition using state-of-the-art sensors/accelerometers.

In this paper, the technological gap between the measurement resolution of the state-of-the-art sensors and emerging devices is identified for passive seismic monitoring. It shows design possibilities using capacitive sensing techniques and motivates further work in developing optimized sensor solutions.

Finally a solution has been provided with specification to design such an accelerometer. To enhance the resolution and sensitivity, a dimension in the order of millimeters larger than conventional MEMS dimensions is required. Moreover, technological issues including reducing parasitic capacitance by increasing dielectric thickness and reducing air pressure for less damping impact beyond 1-10 Torr are among the constraints hindering prospective designs.

In synopsis, piezoelectric accelerometers demonstrate the most astounding estimation range, shock limits, and operating temperature, capacitive accelerometers the least power utilization and volume, and piezoresistive accelerometers the vastest frequency response.

\section{Sensors in Seismology}

Seismic study determines that the effective exploration technique for imaging the geology is active seismic imaging. Previously, explosives or vibroseis trucks are utilized for

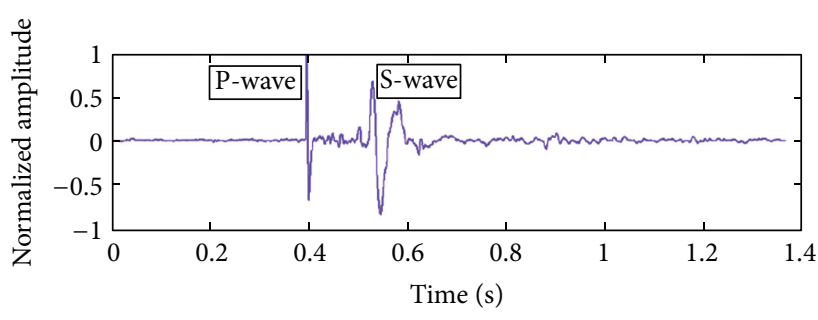

Figure 13: A "good" occurrence of P- and S-wave arrivals in time domain [44].

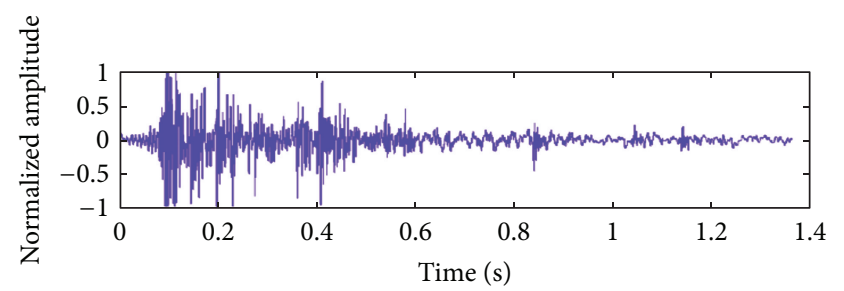

FIGURE 14: A random "noise" event at time domain [33].

generating seismic energy sensed by the network of seismic sensors, which may provide the information that determines the prospective oil and gas traps. In view of received sensor data, a 3D stratigraphy map is developed. This $3 \mathrm{D}$ map may help in determining the position of hydrocarbon depositions. Moreover, the increasing demand and supply of oil and gas need industries to explore more hydrocarbons from previous $50 \%$ to $80 \%$ by identifying accurate information about hydrocarbon deposition $[44,45]$. Conventional techniques cannot provide the correct information about the petrophysical properties of reservoir because the rock pores having hydrocarbon affect the physical properties of the rock which in turn cause poor energy sensed through seismic sensors. One of the key solutions for accurate information is passive seismic imaging technique. This technique uses naturally happening seismic signals like earth quake, microtremors, and ocean waves for subsurface imaging and structuring. In comparison of conventional technique having sensing frequency in the range of $10-300 \mathrm{~Hz}$, passive seismic technique monitors the lower frequency waves (below $10 \mathrm{~Hz}$ ) which may travel a long distance through the earth's crust without attenuation.

An example of "Good" event having occurrences of Pwave and S-wave at time domain is showed in Figure 13. On the basis of the discrete and impulsive P-wave and S-wave arrivals, the event is termed "Good" event [33].

Also, it is shown clearly that frequency of S-wave decreases as the frequency of P-wave increases. A random "noise" event occurring at time domain with indeterministic properties of "Good" events is shown in Figure 14 [33].

In the area of reservoir monitoring, passive seismic have applications for recording microseismic signal at natural frequency for the exploration and exploitation of the hydrocarbons (i.e., oil and gas) [131]. The study of passive seismic at variant frequency identifies that information about prediction of hydrocarbon reservoir is found at low frequency of less than $10 \mathrm{~Hz}[1-5,132]$ as depicted in Table 9. 
TABLE 9: Technical description of seismic data acquisition technique at low frequency.

\begin{tabular}{lccc}
\hline Frequency range focused & Technique used & Advantage & Disadvantage \\
\hline $\begin{array}{l}\text { Modeling frequency: } 50-60 \mathrm{~Hz} \\
{[25]}\end{array}$ & $\begin{array}{c}\text { Spike deconvolution for low } \\
\text { frequency modeling }\end{array}$ & $\begin{array}{c}\text { (i) Low-cut filter is used to } \\
\text { attenuate low frequencies. }\end{array}$ & $\begin{array}{c}\text { (i) Need for recovery of broad } \\
\text { signal bandwidth. } \\
\text { better P-wave and S-wave seismic } \\
\text { section. }\end{array}$ \\
\hline
\end{tabular}

(i) Signal is reflected from a thin,

water- $\left(\mathrm{S}_{w}\right)$ or oil-saturated $\left(\mathrm{S}_{h}\right)$ layer.

Modeling frequency: $1 \mathrm{KHz}$

Acquired seismic frequency:

$12 \mathrm{~Hz}$

Reflectivity at $40 \mathrm{~Hz}$ [26]

(i) Ultrasonic experiment

(ii) Seismic data analysis (ii) Frequency dependent amplitude and phase reflection attributes have been utilized for observing and identifying thin liquid saturated layers.

i) Variable depth streamer for data acquisition is better for

(i) 3D acoustic inversion

(ii) Variable depth streamer: seismic data acquisition (iii) 3D elastic inversion: comparison technique

inversion and provides missing
Missing frequency: 5-10 Hz [27] low frequencies directly.

(ii) Left side lobe of the wavelet is proposed to reduce/less interference in the seismic signal results in less ambiguity in inversion.

(i) Imaging at low frequencies results in robust amplitudes for individual frequency components of propagating wavelet.

(ii) Frequency based seismic imaging permits characterizing the subsurface fluid reservoirs. (i) Strong attenuation in the layer affects summation of multiples.

(ii) Layers with higher attenuation create travel time delays, which increase as frequency approaches zero. (i) There is variation in resulting inversion due to high variation in acquisition frequency.

(ii) Broadband inversion may cause obtained results outside the target zone.
Reflection: $<15 \mathrm{~Hz}$

Amplitude: $40 \mathrm{~Hz}$ [28] (i) AVO attribute analysis

(ii) VSP analysis

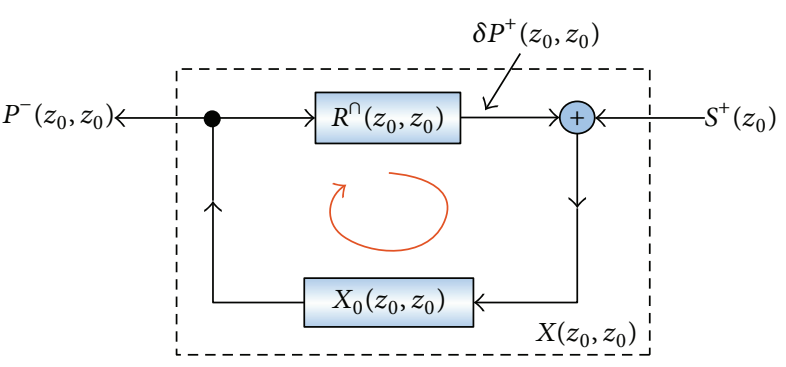

FIGURE 15: A feedforward model representing the upgoing and downgoing wavefields in conventional seismic acquisition [130].

detectors are normally placed at or near the earth's surface, depicted in Figure 15 [133]. It demonstrates schematically upand downgoing wavefields happening at the reflecting surface $\left(z_{0}\right)$, while the wavefields are going "along" the surface being overlooked.

Accordingly, consider a matrix $X_{0}\left(z_{0}, z_{0}\right)$ having a multidimensional transfer function of the subsurface $\left(z>z_{0}\right)$. Here, each variable of $X_{0}\left(z_{0}, z_{0}\right)$ characterized as the impulse response of the wavefield occurred from a unit dipole source at $z_{0}$ and is further sensed by a unit pressure sensor at $z_{0}$. Also, the subscript " 0 " in $X_{0}$ symbolizes that earth's surface has a free reflection boundary; that is, a single round-trip (mean
3.1.1. Active Seismic Imaging Method. In the acquisition of the active seismic data a feedback model has been implemented which is based on the principal that both sources and (i) Quantitative analysis of AI (as frequency) requires NMO

(ii) Conventional seismic processing software does not processing

Based on Table 9, it is clear that the type of geophones used in active seismic acquisition has greater size and is linearly proportional to the velocity over the resonance (about $10 \mathrm{~Hz}$ ) [25-28]. Therefore, a new design of the accelerometer is defined which offers a minimal signal roll-off, small size, and weight solution to the larger arrays Since the existing device and the sensor are unable to record at this frequency, various types of sensor are studied (discussed in Section 4). Based on sensor analysis, it is is the best replacement of existing seismological equipment. Capacitive accelerometers performed well in low bandwidth, exploration is an ongoing and promising research topic with the benefit of being environmentally friendly and of low cost.

\subsection{Comparison of Technical Structure of Active and Passive Imaging}


two-way time) has been estimated by the seismic signal from the subsurface (from $z_{0}$ to $\left.z_{0}\right) . X_{0}\left(z_{0}, z_{0}\right)$ has been utilized as the multidimensional wavefield operator, which defines the wavefields at the reflection free acquisition surface $z_{0}$, $P_{0}^{-}\left(z_{0}, z_{0}\right)$, as

$$
P_{0}^{-}\left(z_{0}, z_{0}\right)=X_{0}\left(z_{0}, z_{0}\right) S_{0}^{+}\left(z_{0}, z_{0}\right)
$$

or

$$
\begin{aligned}
P_{0}^{-}\left(z_{0}, z_{0}\right)= & X_{0}\left(z_{0}, z_{0}\right) \delta P^{+}\left(z_{0}, z_{0}\right) \\
& +X_{0}\left(z_{0}, z_{0}\right) S_{0}^{+}\left(z_{0}, z_{0}\right)
\end{aligned}
$$

with combining

$$
\delta P^{+}\left(z_{0}, z_{0}\right)=R^{\cap}\left(z_{0}, z_{0}\right) P_{0}^{-}\left(z_{0}, z_{0}\right) .
$$

In (25a) source matrix $S_{0}^{+}\left(z_{0}\right)$ signifies the downgoing wavefield of one physical source (array) at $z_{0}$.

However $X_{0} S^{+}$stands for the upgoing primary wavefields (one round-trip) and $X_{0} \delta P^{+}$stands for the upgoing multiplescattering wavefields (many round-trips).

Furthermore, from (25a)-(25c) it can be simply derived that

$$
\begin{aligned}
X_{0} & \left(z_{0}, z_{0}\right) \\
\quad & =\left[I-X_{0}\left(z_{0}, z_{0}\right) R^{\cap}\left(z_{0}, z_{0}\right)\right]^{-1} X_{0}\left(z_{0}, z_{0}\right),
\end{aligned}
$$

representing the complexity of $X$ relating to $X_{0}$. On comparing (25a),

$$
P_{0}^{-}\left(z_{0}, z_{0}\right)=X_{0}\left(z_{0}, z_{0}\right) S_{0}^{+}\left(z_{0}, z_{0}\right),
$$

with (25b),

$$
P_{0}^{-}\left(z_{0}, z_{0}\right)=X_{0}\left(z_{0}, z_{0}\right)\left[\delta P^{+}\left(z_{0}, z_{0}\right)+S^{+}\left(z_{0}, z_{0}\right)\right] .
$$

Based on (26b), it can be concluded that the surfacerelated multiple-scattering phenomenon is incorporated into a parameter $X$. However, (26c) signifies that the surfacerelated multiple-scattering is incorporated into the downgoing wavefield $\delta \vec{P}^{+}$and the parameter $X$ determined as $X_{0}$. Such variation between mathematical equations (26b) and (26c) assumes an imperative part in the inversion modeling for seismic imaging [134].

Here, Figure 16 represents the mixed shot record array of five sources at or near the surfaces. Since, during acquisition, zero time delays and large spacing between the sources are considered, resulting incoherent shooting will become simultaneous shooting $[136,139,140]$. The resultants imaging signifies that a passive seismic recording can be measured as a naturally mixed shot record.

\subsubsection{Passive Seismic Imaging Method Based on Downward} Radiating Natural Sources. Initially, it is considered that pseudo sources are set at or close to the surface $\left(z_{0}\right)$, signifying that the background noise is considered as those wavefields generated by the natural sources. However, in passive seismic imaging, response from natural sources has been

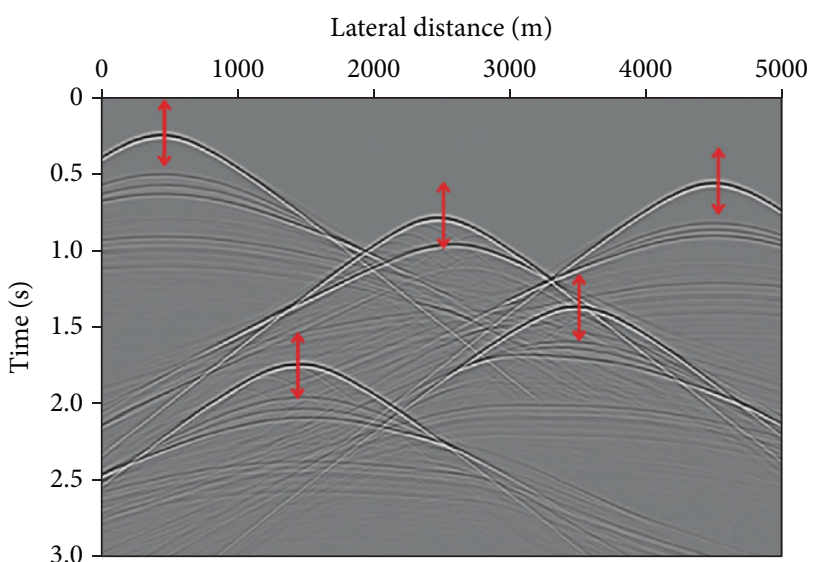

FIGURE 16: A mixed pseudo shot record, generated by using incoherent source array having five source elements at the surface $[135,136]$.

considered as the seismic signal from the subsurface. These sources might be set anyplace at the surface $\left(z=z_{0}\right)$ and in the subsurface $\left(z>z_{0}\right)$ [137]. Henceforth, a noise model has been created which may consider a continuing happening seismic background noise as an indicator to determine the informative data from these noises. This concept is known as seismic interferometry [141]. Furthermore, a relationship by utilizing the wavefield diagram (see Figure 9) has been established between the downgoing source wavefield at the source level $\left(z_{n}\right)$ and the up- and downgoing wavefields at perception level $z_{0}\left(z=z_{0}\right)$. Such relation can be expressed as

$$
\begin{aligned}
\vec{P}^{+}\left(z_{0}, z_{n}\right)= & X_{0}\left(z_{0}, z_{0}\right) \delta \vec{P}^{+}\left(z_{0}, z_{n}\right) \\
& +X_{0}\left(z_{0}, z_{n}\right) \vec{S}^{+}\left(z_{n}\right) \\
= & X_{0}\left(z_{0}, z_{0}\right) \delta \vec{P}^{+}\left(z_{0}, z_{n}\right) \\
& +X_{0}\left(z_{0}, z_{0}\right)\left[W^{-1}\left(z_{0}, z_{n}\right) \vec{S}^{+}\left(z_{n}\right)\right] \\
= & X_{0}\left(z_{0}, z_{0}\right) \delta \vec{P}^{+}\left(z_{0}, z_{n}\right) \\
& +X_{0}\left(z_{0}, z_{0}\right) \vec{S}^{+}\left(z_{0}, z_{n}\right),
\end{aligned}
$$

where

$$
W^{-1}\left(z_{0}, z_{n}\right)=X_{0}^{-1}\left(z_{0}, z_{0}\right) X_{0}\left(z_{0}, z_{0}\right)
$$

Figure 17 describes the feed-forwarded model which is based on modeling by downward radiating natural sources at and below the surface $(n \geq 0)$ and recorded at the surface $\left(z_{0}\right)$. Here, the response parameter is a real estimation of a source (array) at the depth level $z_{n}$.

\subsubsection{Passive Seismic Imaging Method Based on Upward} Radiating Natural Sources. In this phase, like active seismic background noise similar type of natural source's response is considered, but the direction has been changed to the 


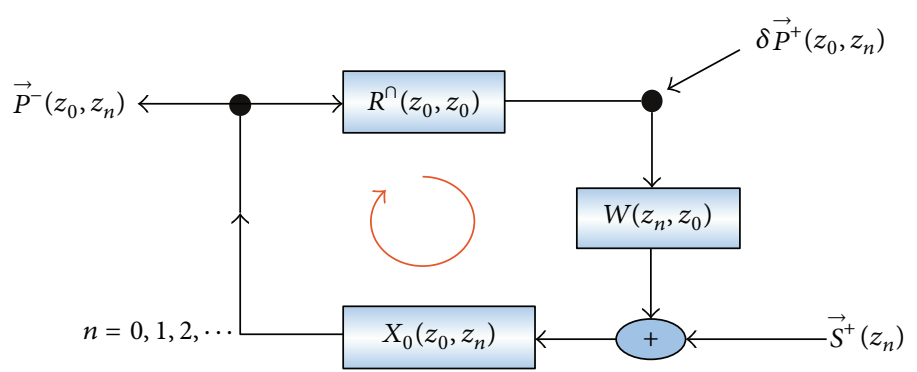

FIGURE 17: Feed-forwarded model for up- and downgoing wavefields, modeled based on downward processing [137, 138].

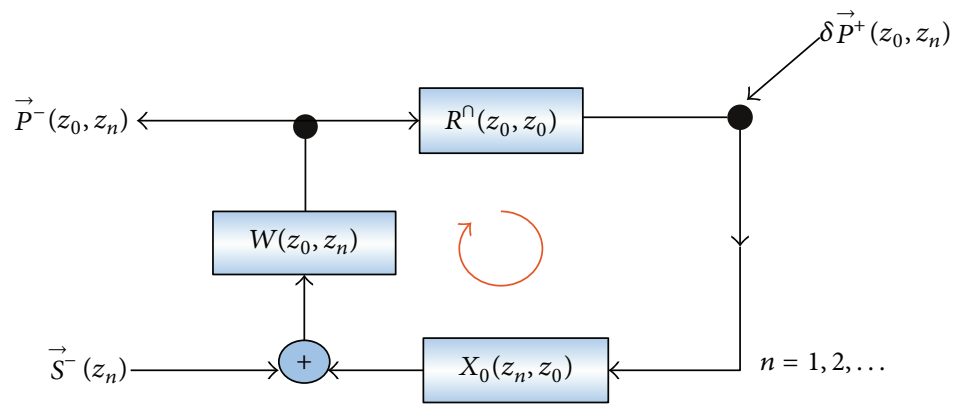

FIGURE 18: Feed-forwarded model for up- and downgoing wavefields, modeled based on downward processing $[137,138]$.

contribution of "upward" radiation. Figure 18 depicts the resultants response which describes the correlation between the upgoing source wavefields at the source level $\left(z_{n}\right)$ and the up- and downgoing wavefields at observation level $z_{0}$. Such result can be expressed as

$$
\begin{aligned}
\vec{P}^{-}\left(z_{0}, z_{n}\right)= & X_{0}\left(z_{0}, z_{0}\right) \delta \vec{P}^{+}\left(z_{0}, z_{n}\right) \\
& +W\left(z_{0}, z_{n}\right) \vec{S}^{-}\left(z_{n}\right) \\
= & X_{0}\left(z_{0}, z_{0}\right) \delta \vec{P}^{+}\left(z_{0}, z_{n}\right)+\vec{S}^{-}\left(z_{0}, z_{n}\right) .
\end{aligned}
$$

Figure 18 describes the feed-forwarded model which is based on modeling by upward radiating natural sources at and below the surface $(n>0)$ and recorded at the surface $\left(z_{0}\right)$. Here, the response parameter is a real estimation of a source (array) at the depth level $z_{n}$.

3.1.4. Statistical Description of the Modeling. In the statistical analysis of the above designed model, the above defined expressions have been utilized on an exceptionally straightforward medium. Such medium has one horizontal reflector and a free surface, depicted in Figure 19. The stepwise construction of this medium signifies imaging in Figure 19(a), describing the conventional active seismic record, where one primary and the surface multiples have been identified and indicated by a mathematical expression in (25b). In continuation, Figure 19(b) describes the measurement of a response from a downward radiating noise burst by implementing (27a) and (27b) while Figure 19(c) describes the upward transmitting patterns by estimating (28).
From these figures and equation implementation, it is clearly defined that the occurrence of response and its multiples takes place directly. Moreover, Figure 19(d) precisely demonstrates the effect of such multiples, that is, the noise bursts, being the summation of Figures 19(b) and 19(c), respectively.

Figure 19 defines the straightforward medium which has one horizontal reflector and a stress-free surface. Here, Figure 19(a) describes the impulsive source at the surface, while Figure 19(b) shows at first layer the downward radiating noise source. Similarly, Figure 19(c) shows at first layer the upward radiating noise source. Finally, Figure 19(d) establishes the omnidirectional noise source in the first layer of imaging. Overall, it has been signified that different sources determine the different resultant responses. For example, Figure 19 clearly proved this statement by demonstrating that all sources defined here produce the different responses at or near the subsurface of seismic imaging.

3.2. Example Showing the Processing of Active and Passive Seismic Imaging and Their Significance. In this example, for a mixed seismic data response, inversion method followed for known and unknown sources is illustrated. Here, three reflectors are utilized to measure the response for the subsurface modeling (see Figure 20(a)). To begin with, without considering surface-related multiples, $X_{0}$, the multidimensional impulse response of the subsurface has been produced. However, Figures 20(b)-20(d) describe the threecolumn impulsive response of $X_{0}$. It results in naturally occurring mixed recording at the subsurface. Therefore, in the next modeling step, surface-related multiples have been implemented, that is, from $X_{0}$ to $X$. 


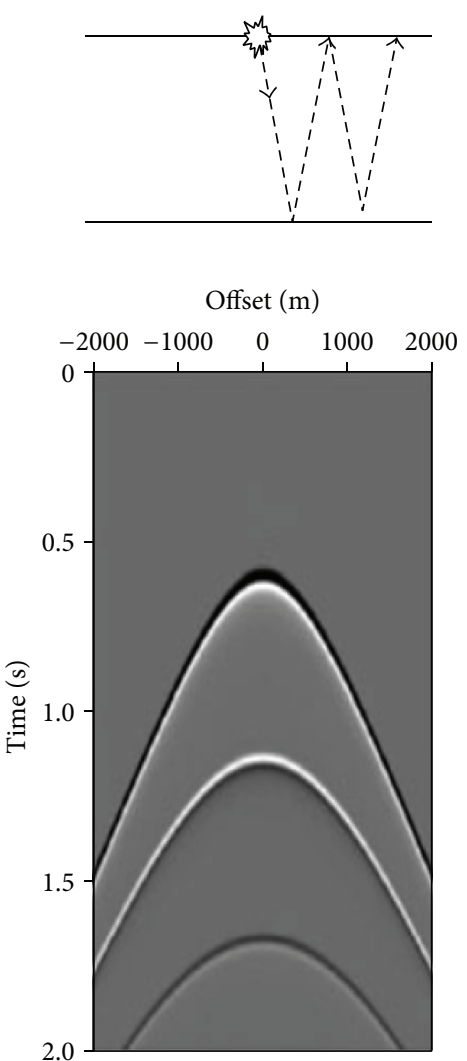

(a)

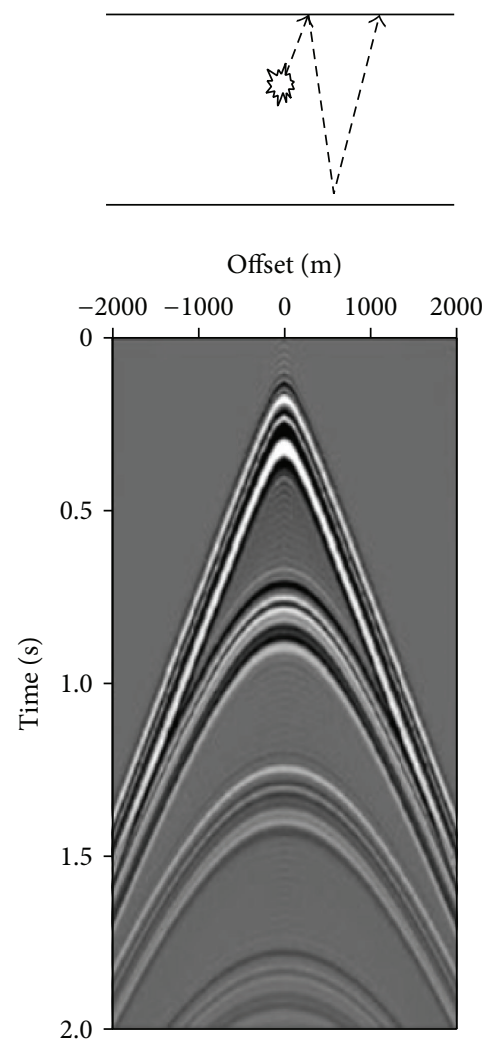

(c)

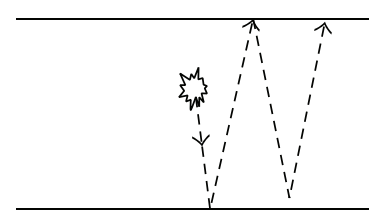

Offset $(\mathrm{m})$

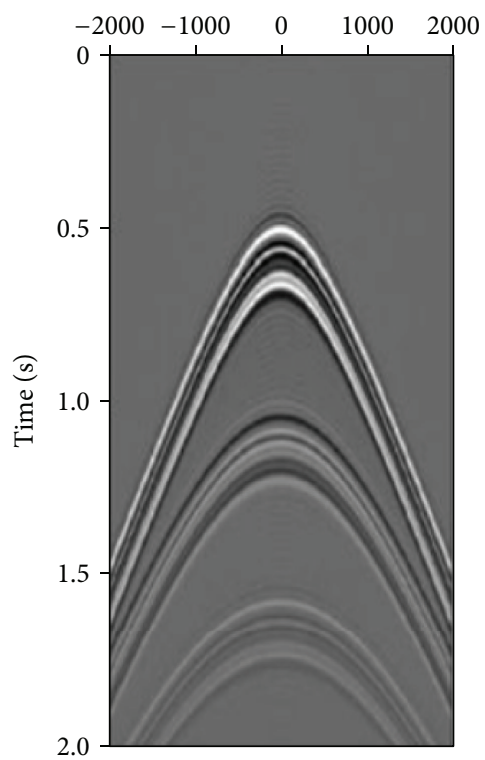

(b)

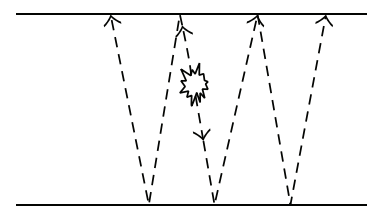

Offset $(\mathrm{m})$
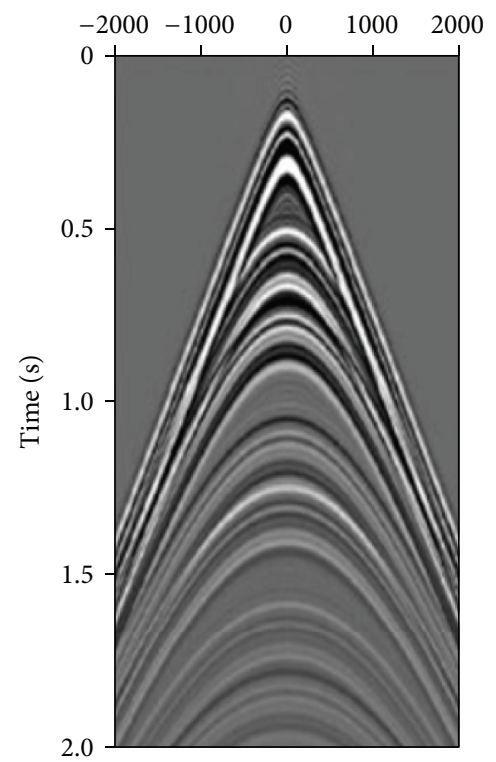

(d)

FIGURE 19: Representing four distinctive estimation configurations and the corresponding upward travelling waves at the surface $\left(\vec{P}^{-}\right)[137$, 138]. 


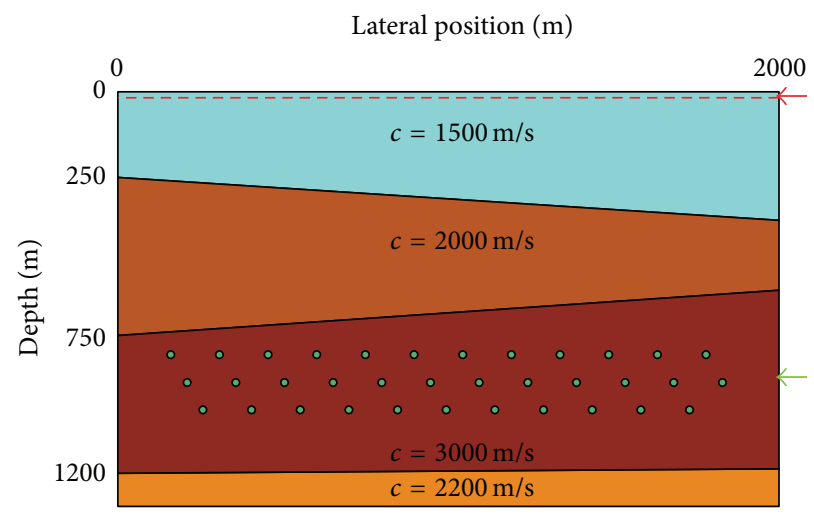

(a)

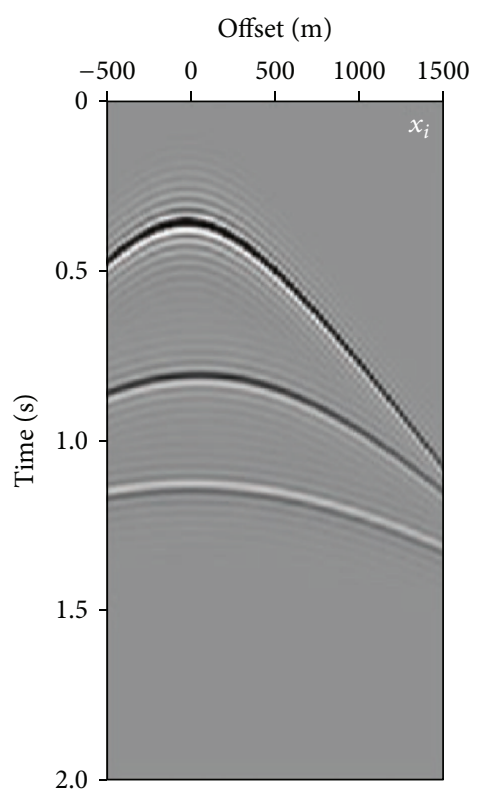

(b) Source at $x=500 \mathrm{~m}$

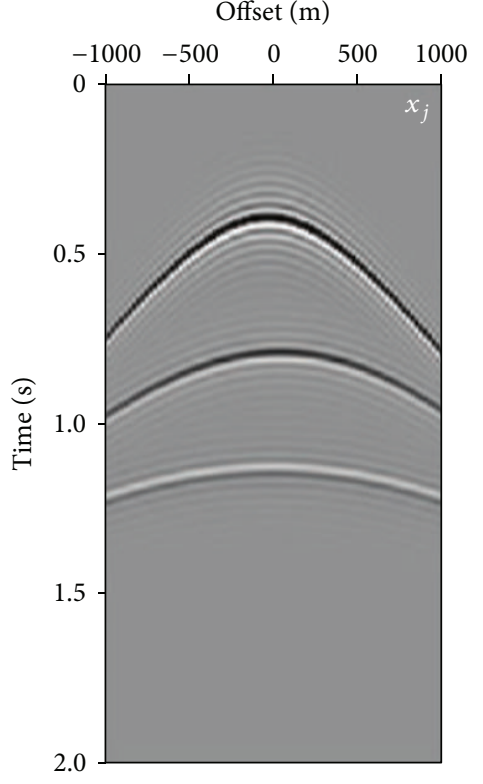

(c) Source at $x=1000 \mathrm{~m}$

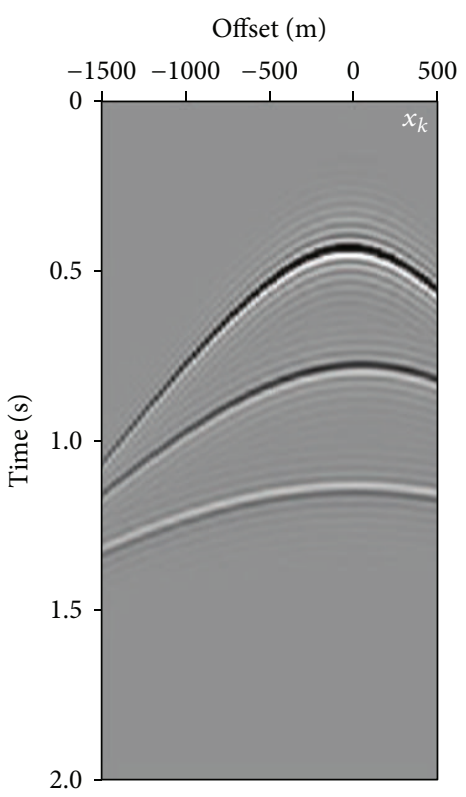

(d) Source at $x=1500 \mathrm{~m}$

FIgURE 20: A Subsurface modeling to generate active and passive seismic data $[137,138]$.

According to Figure 20, a subsurface model has been created such that Figure 20(a) describes the formation of the surfaces with their respective depths. Here, pseudo sources have been used for imaging, placed at the surface $(z=$ $0)$. It also considers the natural sources that are placed in the subsurface between $z=800$ and $z=1000 \mathrm{~m}$ and represented as the green dots. In continuing, Figures 20(b)20 (d) demonstrate the three band-limited impulse responses (three columns of $X_{0}$ ). These responses occurred without considering the internal multiples.

Furthermore, for clear demonstration, first "active" seismic data are considered, imaged by utilizing one incoherent array of $81 \mathrm{P}$ sources. Such sources have been considered in such a way that each source has known firing times and positions at the surface $\left(z_{0}\right)$. Then, the aggregate response of the generated synthetic incoherent source array has been simulated by superimposing 81 distinct shot records with a variation in delay time response. This processing of imaging is called blending process, which results in the recording time of the resultant mixed measures up to $35 \mathrm{~s}$. From this recorded time, $5 \mathrm{~s}$ has been demonstrated in Figure 21(a), where, for active imaging, the convolution of the response has been implemented by utilizing a nonzero phase source wavelet.

In the second case "passive" image data has been implemented such that it consists of 35 unknown microseismic $\mathrm{P}$ sources. The modeling of sources is in such a way that each source has been placed below the second reflector, depicted in Figure 21(a). The reflectors in this modeling have random firing times, having a response time of $5 \mathrm{~s}$. However, the source signature of each hidden source considered a variant dispersive wavelet for convoluting with the response to generate a passive image. The final results estimated as a mixed recording occurred naturally at the subsurface and finally such recorded time response with data has been modeled, as shown in Figure 22(a). 


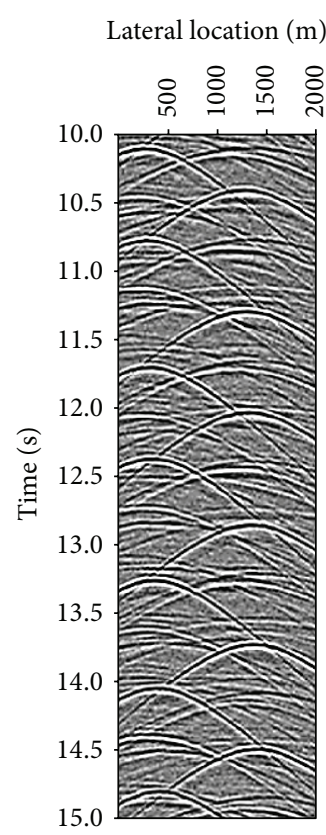

(a) Blended $\vec{P}^{-}$

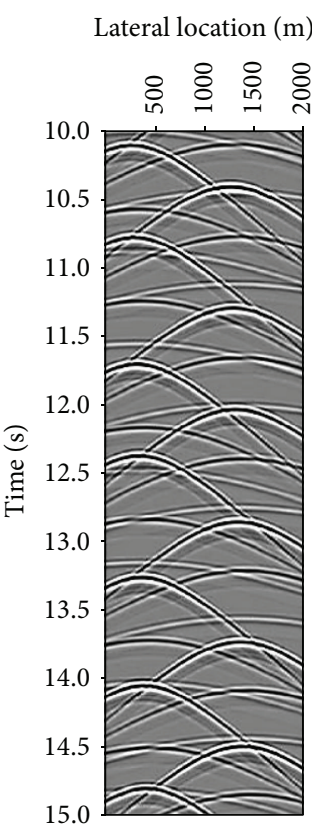

(b) True $\vec{P}_{0}^{-}$

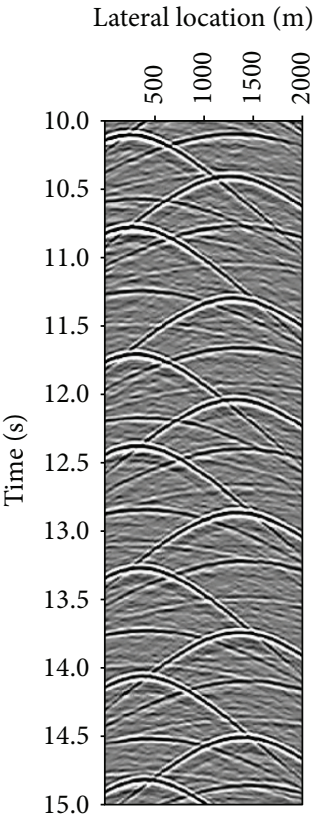

(c) Estimated $\vec{P}_{0}^{-}$

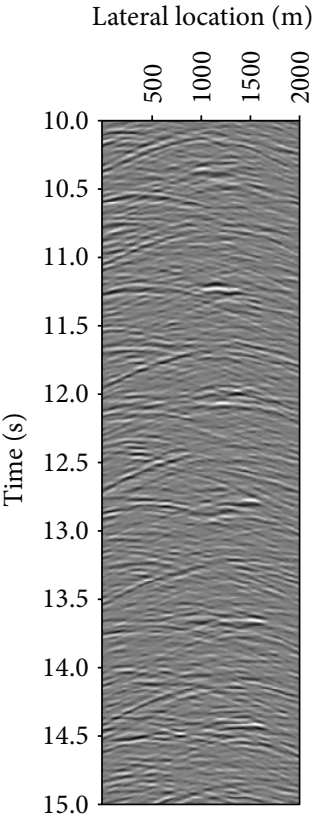

(d) Residual $\vec{E}_{0}^{-}$

FIGURE 21: Mixed shot record (a) with and (b) without a reflecting surface. (c) Resultant image obtained by subtracting the estimated multiples from the input image data. (d) Resultant image obtained by subtracting both estimated primaries and multiples from the input image data [140].

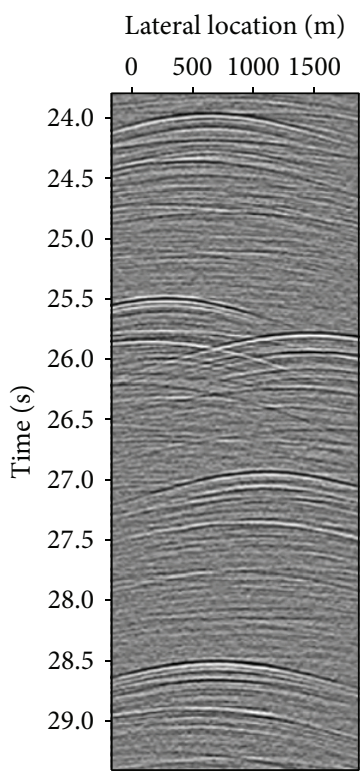

(a) Passive $\vec{P}^{-}$

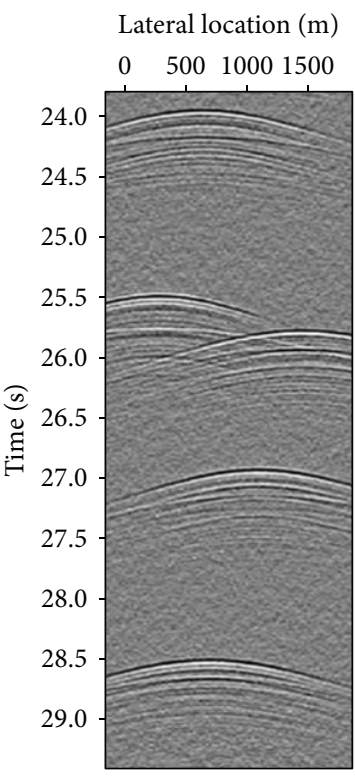

(b) True $\vec{P}_{0}^{-}$

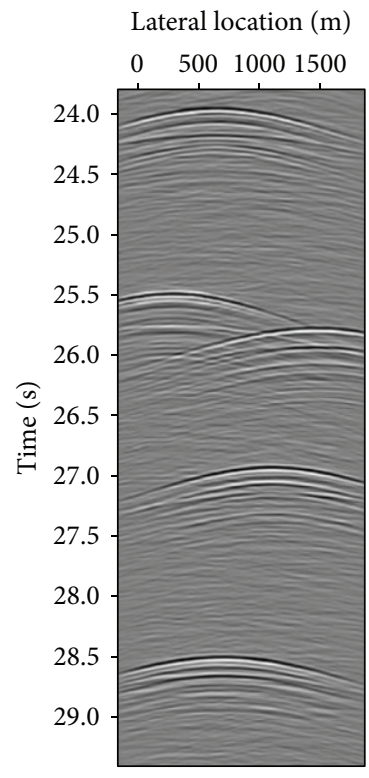

(c) Estimated $\vec{P}_{0}^{-}$

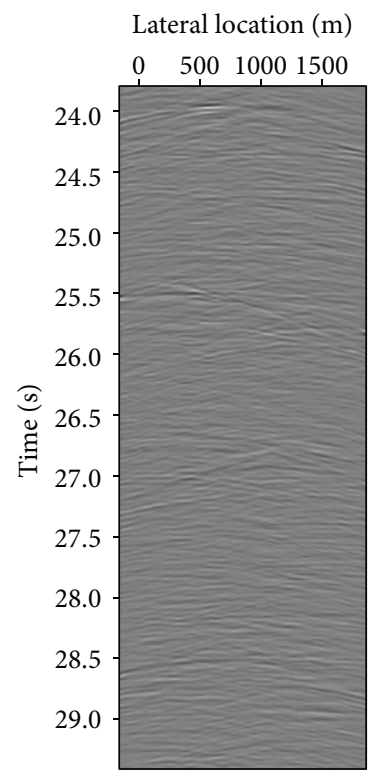

(d) Residual

FiguRE 22: (a) Simulated passive seismic measurements (a) with and (b) without a reflecting surface. (c) Measured resultant data by depriving surface multiples lead to computing the source signatures. (d) Remaining resultant data while subtracting the surface multiples and direct source wavefields $[142,143]$. 


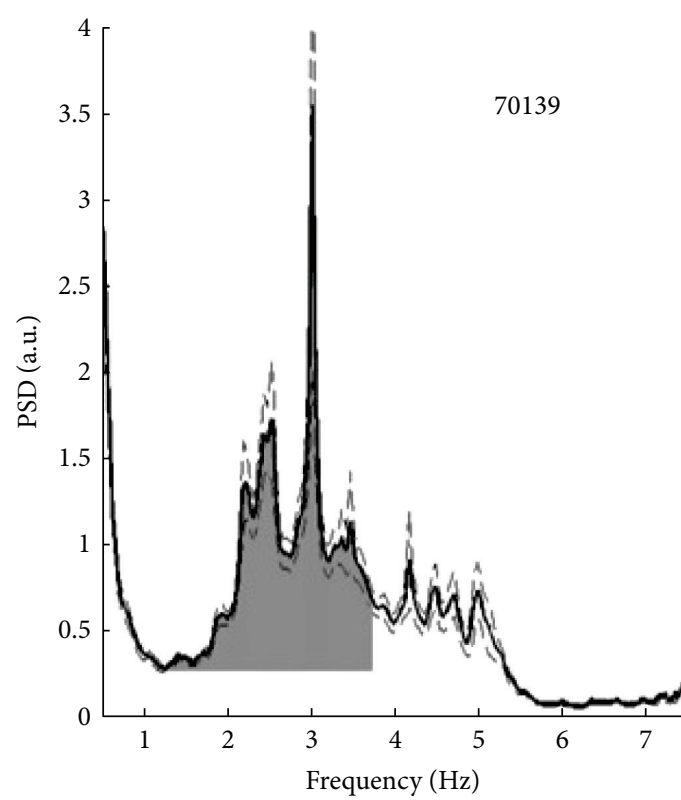

(a)

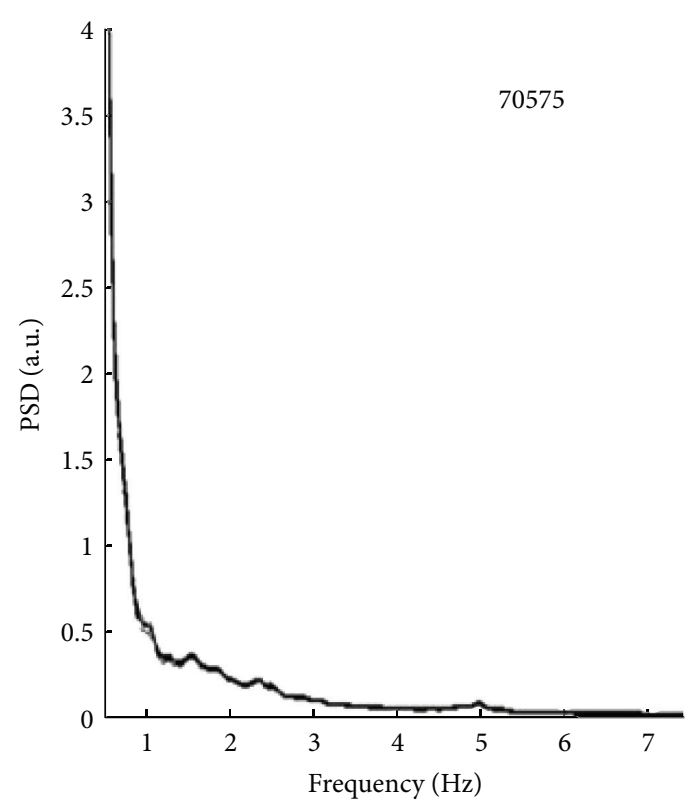

(b)

FIGURE 23: Spectrum (solid line) representing the passive seismic wavefield (vertical surface velocities) from a frequency range of 0.5 to $7.4 \mathrm{~Hz}$ [22].

Based on the experimental and modeling analysis, active seismic data responses generate more multiples than passive seismic response. Such multiples may affect the resultant impulsive response of clear reservoir monitoring by poor imaging. Since this model follows active seismic acquisition, it may consider the background noise as a seismic signal which provides the important information about the dynamics of the subsurface [143]. But it may also affect the geology of the reservoir by generating different multiples at different bandwidth. It also identifies that passive seismic recordings can also generate the seismic multiples, but by unknown natural resources, which may not affect the overall stratigraphy of the subsurface. Henceforth, it has been concluded that the total lack of information about the natural sources (firing time, signature, and position) becomes a key principal difference between the active and passive seismic imaging methods.

\section{Passive Seismic Surveys}

A study analysis of the growing number of stratigraphy surveys over variant oil and gas fields signifies the existence of spectral anomalies in the passive seismic wavefield, that is, microtremors, having a high degree of relationship with the localization of hydrocarbon reservoirs [22, 144151]. Such microtremors work as a reservoir indicator to optimize the well placement during exploration, appraisal, and development. However, in consideration of the conventional seismic technologies, the microtremor which investigates the hydrocarbon reservoir is generally passive. Such microtremors work in such a way that they do not require pseudo seismic sources for excitation. A broad review over a tight gas reservoir and an adjoining exploration area in Mexico has been considered for data analysis. The data have several hundred stations with three-component broadband seismometers placing over approximately $200 \mathrm{~km}^{2}$ for the data analysis [22]. Experiments on worldwide sites with known hydrocarbon reserves were initially reported [2]. At narrow frequency range of $1.5-4 \mathrm{~Hz}$ and amplitude $0.01-$ $10 \mu \mathrm{m} / \mathrm{s}$, a tremor-like signal has been observed in defined location. Similar observations were also found in Volga-Ural oil bearing province in Tarasan [6] and in Mexico for tight gas field (see Figure 23) [22, 144].

The reservoir system named Paleocene Wilcox has four fundamental production intervals such that the top deltaic sequences are considered best producers, followed by three more layers of sandstone. The total sand thickness varying between 120 and $30 \mathrm{~m}$ occurred by block-nose erosion on the shallowest compartments, having faulting blocks, and variation in lateral thickness of the sediments. Here, 20 ultrasensitive portable three-component (3-C) broadband seismometers (frequency range, $0.03-50 \mathrm{~Hz}$; sampling rate, $100 \mathrm{~Hz}$; sensitivity, $1500 \mathrm{~V} / \mathrm{m} / \mathrm{s}$ ) have been utilized for the acquisition of more than 700 estimations of the omnipresent seismic wavefield at the surface over around $200 \mathrm{~km}$ [22]. In continuing with the data analysis, the data acquisition has two-matrix layout acquired continuously over a 3-month period, having $1000 \mathrm{~m}$ node spacing. The only difference between the two matrixes is that second matrix has staggered offset in comparison to the middle of the first matrix, which may lessen the average spacing between the nodes to $700 \mathrm{~m}$.

According to Figure 23, the dashed line shows the standard deviation of the mean spectrum. Figure 23(a) 
shows recorded station named 70139 over a known gas field, while Figure 23(b) recorded a station named 70575 over a range with no hydrocarbon potential [22]. A linear frequency scale has been used to estimate the shaded surface, illustrated as PSD-IZ value. Here, the amplitudes for both stations have been compared directly without applying a scaling factor. Noise floor variations have been considered in the data obtained by estimating the individual minimum amplitude of each spectrum within a frequency range of 1 and 1.7 Hz. The survey analysis shows a minimum in this range, signifying that slight variation in the frequency range has been considered for the next surveys [144]. The integral over this minimum amplitude computes the PSD-IZ value, where IZ describes the integral of the $z$-component. It considers the whole energy anomaly over a well-defined background level (i.e., the minimum within a frequency range of 1 and $1.7 \mathrm{~Hz}$ ), which has not been restricted to peak strength at specific frequencies. Thusly, uncertain high amplitude peaks appeared because of human activity at the surface (e.g., the narrowband peaks at a frequency range of 2.5 and $3 \mathrm{~Hz}$ in Figure 15), which signifies that it has not contributed to the PSD-IZ values [22, 144, 145].

4.1. Maximum Spectrum Peaks by Using Frequency Shift. According to frequency shift, it has been observed that the spectrum over hydrocarbon reservoirs consists of spectral peaks within a narrow frequency range of $1.5-4 \mathrm{~Hz}$, recognized as oil- and gas-reserves [144]. This survey shows that the spectral peaks have been appearing over the acquired data spectra having a variable frequency range (e.g., at 2.5, 3, 4, and $5 \mathrm{~Hz}$ ), depicted in Figure 23. However, the number of peaks and their relative/absolute amplitudes have larger variation with the variation of time and location. Such variation creates a difficulty in the making of consistent map which follows the average amplitudes of the estimated spectra [144]. Therefore, this method focused on estimating the frequency values corresponding to the maximum spectral peak rather than amplitude spectra. This may help in providing the true information about the anomalies, such that a most significant peak frequency has been estimated within the frequency band of interest.

According to Figure 24, the specific frequency of the maximum spectra peak has been considered, having a range from $1.5 \mathrm{~Hz}$ to $3.7 \mathrm{~Hz}$ by applying standard Kriging interpolation. Here, the estimated source signature shows independency from the PSD-IZ and V/H attributes, as shown in Figure 23. Finally, two areas have been identified which have a relatively high-frequency signature such that [150]

(i) first area signifies the survey having producing area (solid ellipse);

(ii) second area represents an exploration zone (dashed circle).

Moreover, it has been concluded that the data utilized here is on the surface, a complicated mixture of variant wave types and location. However, it has been identified that survey area has stable trends which may consist of the polarization attributes in the frequency band between 1 and

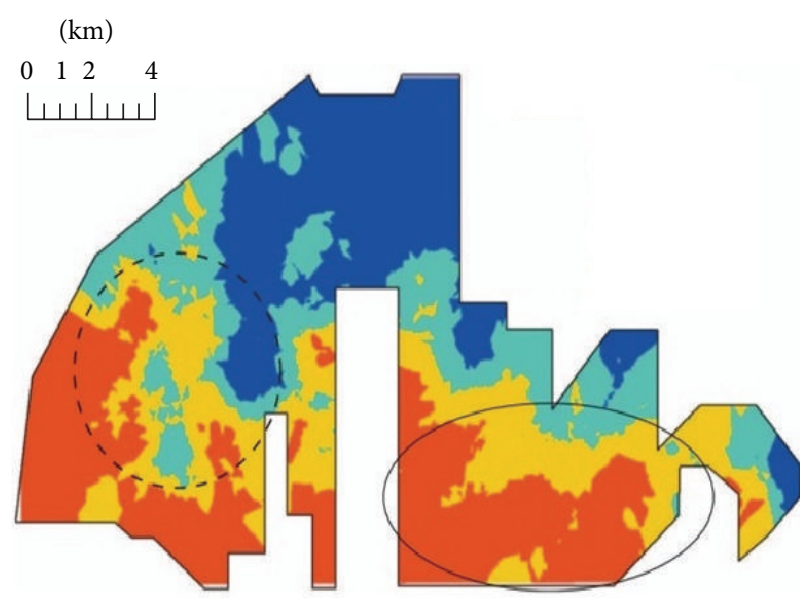

Peak frequency

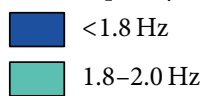

$2.0-2.4 \mathrm{~Hz}$ $>2.4 \mathrm{~Hz}$

FIGURE 24: A determining survey map of the formation having frequency of the maximum peak within a frequency range from $1.5 \mathrm{~Hz}$ (blue) to $3.7 \mathrm{~Hz}$ (red) $[22,144]$.

3.7 Hz. In Figure 17, there is a direct correlation between the estimated PSD-IZ values and the computed drainage radii of the production wells. Since the production noise sources (e.g., tube waves or pumps) have unlikely explanation at the surface, still some ambiguity remains such as formation conduction. It is because of the production reservoir which may not be strictly suited with a seismic area (i.e., production facilities).

\subsection{Seismic Attributes Predicted Hydrocarbon versus Drilled} Wells Based on Determined Survey. According to the exploration zone of this survey, one big PSD-IZ energy pattern is observed which has been marked with a dashed circle in Figure 16. The interpretation of $\mathrm{V} / \mathrm{H}$ signal and the relatively high frequency at maximum peak in Figure 16 signifies a precise indicator for hydrocarbons prediction [146]. Hence, two successful wells have been drilled in this determined zone, where generated passive seismic data signifies the existence of gas-bearing sediments (see Figure 25). This resultant occurrence of gas-bearing represents a lower production rate, which may cause the reservoir rock to be less permeable [147]. Since the wells have been drilled after the survey has been determined, the predictive attributes indicating hydrocarbon presence are not affected by the production activity or other significant human activity in the vicinity. Therefore, successful production wells at production zone 2 define the zone with a relatively high PSD-IZ value (Figure 25) [22].

Seismic tremors with different spectral densities were recorded using ultrasensitive multicomponent seismometers. Drilled wells after the survey confirmed that tremor signals were related to presence of gas in subsurface. The exact field productivity depends on the reservoir permeability. Therefore, it could not be directly inferred from passive seismic data $[1,29]$. The literature study signifies that the 


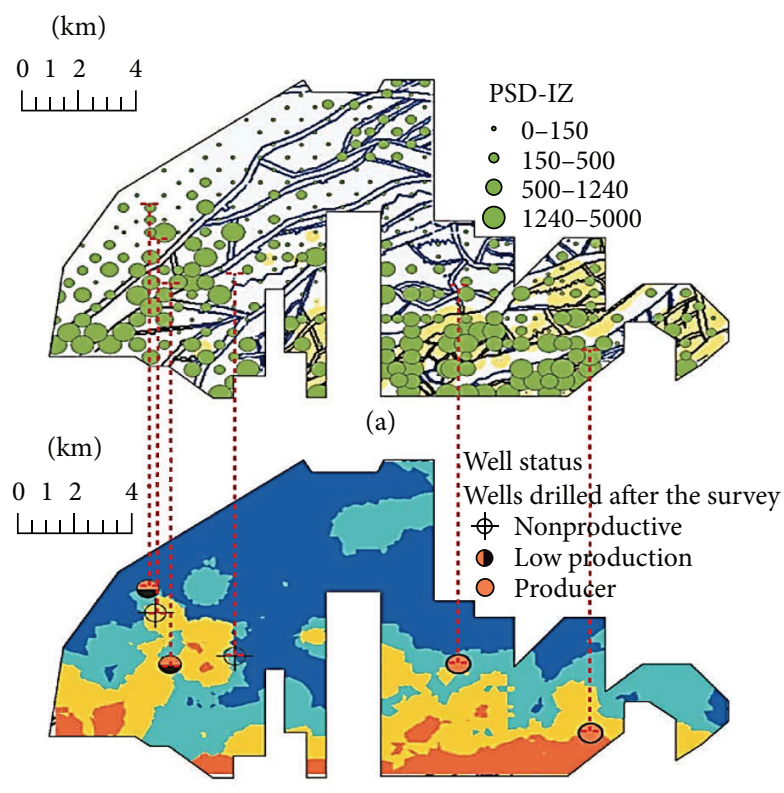

(b)

Figure 25: Correlation example taken from [22], between Power Spectral Density (PSD) of passive seismic survey and well drilled after the survey: (a) Power spectral Density in $Z$ direction (PSD-IZ); (b) status of well drilled after the survey [22].

observed tremor signals have been correlated with hydrocarbon reservoir for the supplying seismic-acoustic energy for filtering/mixing hydrocarbon impacts on reservoir subsurface $[2,5,6,8,21,22,44,127]$. However, others have expressed some doubts on underlying theory of the technique and its applicability to different geologies and its repeatability $[24,29,41]$.

Passive seismic signals are narrow banded $(1-30 \mathrm{~Hz}$, as shown in Table 10), of low frequency, and of low amplitude; for instance, the peak ground acceleration (PGA) for tremor signals can fall below $80 \mathrm{mg}$ for passive seismic [7, 22, 32]. Low cost and environmentally friendly features of passive seismic make it an economically viable option. It also signifies from Table 10 that capacitive MEMS based accelerometer is better than other MEMS based accelerometers in the carbonate reservoir. This capacitive accelerometer determines that self-noise level signifies $9.8 \mathrm{ng} / \sqrt{\mathrm{Hz}}$ at periods below $0.2 \mathrm{~s}$ (frequencies above $5 \mathrm{~Hz}$ ).

However, analysis and processing of seismic data signify that the very low end of the seismic spectrum, under $10 \mathrm{~Hz}$, consists of precise information for the direct identification of hydrocarbon reservoirs [143] and also acts as a universal direct hydrocarbon indicator (DHI) [152]. Such results determine the improved possibilities for localizing the production zone accurately, potentially helping in reducing costs in drilling and well production.

Furthermore, passive seismic sensing describes its necessity in the low frequency spectral region due to the fact that the man-made seismic energy generator (like vibrators) critically affects the formation and does not have much capability to produce sufficient energy in the low frequencies area needed. Therefore, it requires a significant type of passive seismic sensors like geophones and MEMS seismic sensors with conventional sensing below the frequency spectrum less than $10 \mathrm{~Hz}$. Hence, based on the passive seismic sensing requirement a survey has been made as shown in Table 11.

The survey, depicted in Table 11, signifies that passive seismic may require seismometers having high broadband or special low frequency geophones, such as the I/O LF-24 and the Geospace HS-10 [31, 143, 152]. However, these sensors have a relatively higher cost of installation and also may represent their fragile nature, leading to designing a passive seismic sensor of an expensive consideration. Hence, a low frequency sensor named Molecular Electronic Transducers (MTLF1040) Low Frequency Sensor has been discovered. MTLF1040 defines improved performance in the low frequency spectral bandwidth (Table 15). It also produces a higher sensitivity than conventional $1 \mathrm{~Hz}$ and $4.5 \mathrm{~Hz}$ geophones, with lesser cost estimation at the low frequencies formation [31].

\section{Technology Gap of Sensors}

Sensors performance in low frequency measurement is poor due to the physical limitations of sensing elements $[23,153]$. The measurement of the tremor signals is demanding high resolution which is inversely affected by device noise. This can be explained by recalling the 24-bit modern standard digital output of seismic sensors [8]. Considering full scale of $80 \mathrm{mg}$, the minimum detectable acceleration would be $4.7 \mathrm{ng}$. The minimum detectable acceleration is a function of the noise floor and the bandwidth, as shown in following expression:

$$
a_{\min }=\sqrt{\overline{a_{n}^{2}}} \sqrt{\mathrm{BW}} \text {. }
$$

According to (29), for $30 \mathrm{~Hz}$ bandwidth, the collective noise floor should therefore be less than $1 \mathrm{ng} / \sqrt{\mathrm{Hz}}$. The equation also shows the adverse effect of excessive bandwidth on the minimum detectable acceleration. On the other hand, having a large full acceleration would adversely affect the sensitivity which has been described as the total ratio between maximum output voltage, $V_{\mathrm{m}}$, and the maximum acceleration, $a_{\mathrm{m}}$, as shown in

$$
S=\frac{V_{\mathrm{m}}}{a_{\mathrm{m}}} .
$$

Additionally, sensors from leading technology providers (illustrated in Figure 17 and Table 10), however, are not fully capable of capturing passive seismic signals. This is mainly due to their wide bandwidth $[18,23,33]$, larger full scale $[18$, $23]$, and low noise performance at low frequencies [18, 32].

High resolution acquisition for microtremor signals is a crucial market concern for passive seismic hydrocarbon exploration studies. The technological gap between application requirements and performance offered by available and emerging accelerometers motivates the development of dedicated sensing technology. As a result, the measurement resolution is inversely affected. This can be explained by recalling the 24-bit standard output implying a noise density $<4 \mathrm{ng} / \mathrm{rtHz}[63,153]$. This noise density has not been met 
TABLE 10: Hydrocarbon microtremor signal bandwidth.

\begin{tabular}{|c|c|c|c|c|c|c|}
\hline $\begin{array}{l}\text { Min. freq. } \\
(\mathrm{Hz})\end{array}$ & $\begin{array}{l}\text { Max. freq. } \\
(\mathrm{Hz})\end{array}$ & $\begin{array}{l}\text { Type of data } \\
\text { acquisition }\end{array}$ & $\begin{array}{c}\text { Type of device } \\
\text { used }\end{array}$ & $\begin{array}{l}\text { Type of } \\
\text { reservoir }\end{array}$ & Sensitivity & Analysis \\
\hline 1.5 & 4 & $\begin{array}{l}\text { Seismoacoustic } \\
\text { background }\end{array}$ & $\begin{array}{l}\text { Narrowband, } \\
\text { low frequency } \\
\text { tremors } \\
\quad[1]\end{array}$ & $\begin{array}{l}\text { Highly sensitive } \\
\text { ground motion } \\
\text { velocity } \\
\text { receivers; gas } \\
\text { reservoir }\end{array}$ & $\begin{array}{l}1-\mathrm{s} \text { or } 2-\mathrm{s} \\
<1000 \mathrm{~V} / \mathrm{m} / \mathrm{s}\end{array}$ & $\begin{array}{l}\text { The signals weaken at the rim of the } \\
\text { reservoirs and are not observed } \\
\text { outside the reservoir area. } \\
\text { Seismic-acoustic background noise } \\
\text { differs widely. }\end{array}$ \\
\hline 1 & 6 & $\begin{array}{l}\text { Passive seismic } \\
\text { low frequency }\end{array}$ & $\begin{array}{l}\text { Low frequency } \\
\text { microtremors } \\
{[4]}\end{array}$ & $\begin{array}{l}\text { Tight gas } \\
\text { reservoir and an } \\
\text { adjacent } \\
\text { exploration area }\end{array}$ & $1500 \mathrm{~V} / \mathrm{m} / \mathrm{s}$ & $\begin{array}{l}\text { Requiring careful data analysis } \\
\text { using microtremors around } \\
\text { reservoirs with considerable noise } \\
\text { (e.g., production noise) because (a) } \\
\text { anomalies caused by noise can be } \\
\text { misinterpreted as being caused by } \\
\text { the reservoir or (b) such a } \\
\text { high-noise environment can } \\
\text { overwhelm the signal. }\end{array}$ \\
\hline 2.5 & 7 & Microseismic & $\begin{array}{l}\text { Long-period } \\
\text { microtremor } \\
{[3]} \\
\end{array}$ & $\begin{array}{l}\text { Sedimentary } \\
\text { basin }\end{array}$ & Not specified & $\begin{array}{l}\text { Nature of the soil showing variation } \\
\text { in resonance properties. }\end{array}$ \\
\hline 1 & 10 & $\begin{array}{l}\text { Passive seismic } \\
\text { low frequency }\end{array}$ & $\begin{array}{l}\text { Microtremor } \\
{[24]}\end{array}$ & $\begin{array}{l}\text { Basement rock } \\
\text { with oil bearing } \\
\text { capability }\end{array}$ & Not specified & $\begin{array}{l}\text { Variation in the field of microseisms } \\
\text { due to the level of anthropogenic } \\
\text { noise. }\end{array}$ \\
\hline 1.9 & 3 & $\begin{array}{l}\text { Passive seismic } \\
\text { low frequency }\end{array}$ & $\begin{array}{c}\text { 3-C broadband } \\
\text { seismometer } \\
{[29]}\end{array}$ & Giant oil field & Not specified & $\begin{array}{l}\text { Identifying low energy attribute } \\
\text { showing low potential. } \\
\text { Required improvement in data } \\
\text { acquisition and processing } \\
\text { methods. }\end{array}$ \\
\hline 2 & 13 & Passive seismic & $\begin{array}{l}\text { Microtremor } \\
\text { [17] }\end{array}$ & $\begin{array}{l}\text { Sedimentary } \\
\text { basin of the } \\
\text { lower cretaceous }\end{array}$ & $1600 \mathrm{~V} / \mathrm{m} / \mathrm{s}$ & $\begin{array}{l}\text { Identified wide variation in the data } \\
\text { resolution in depth. }\end{array}$ \\
\hline 1 & 4 & $\begin{array}{l}\text { Passive seismic } \\
\text { low frequency }\end{array}$ & $\begin{array}{c}\text { 3-C broadband } \\
\text { seismometer } \\
{[18]}\end{array}$ & $\begin{array}{l}\text { Appraisal well } \\
\text { with partially } \\
\text { saturated oil } \\
\text { reservoir }\end{array}$ & 0.025 to $5 \mathrm{~Hz}$ & $\begin{array}{c}\text { Acquired data unable to distinguish } \\
\text { between a purely elastic and a } \\
\text { viscoelastic scattering process. }\end{array}$ \\
\hline 1 & 6 & $\begin{array}{l}\text { Low frequency } \\
\text { passive seismic }\end{array}$ & $\begin{array}{l}\text { 3-C broadband } \\
\text { seismometer }[3]\end{array}$ & $\begin{array}{l}\text { Stacked } \\
\text { reservoirs of } \\
\text { lower cretaceous } \\
\text { (carbonate } \\
\text { reservoir) }\end{array}$ & $2000 \mathrm{~V} / \mathrm{m} / \mathrm{s}$ & $\begin{array}{c}\text { Microtremor signal has no clear } \\
\text { correlation with the microseism } \\
\text { signals. }\end{array}$ \\
\hline
\end{tabular}

\begin{tabular}{|c|c|c|c|c|c|c|}
\hline 0.0125 & 62.5 & Microseismic & $\begin{array}{c}\text { Hewlett- } \\
\text { Packard (HP) } \\
\text { Microelec- } \\
\text { tromechanical } \\
\text { Systems } \\
\text { (MEMS) seismic } \\
\text { accelerometer } \\
\text { (capacitive } \\
\text { sensor) } \\
{[30]}\end{array}$ & Not specified & $\begin{array}{c}3.3616 E+7 \\
\text { counts } / \mathrm{V}- \\
8.4165 E+6 \\
\text { counts } / \mathrm{V}\end{array}$ & $\begin{array}{c}\text { The analysis of self-noise level } \\
\text { signifies } 9.8 \mathrm{ng} / \sqrt{\mathrm{Hz}} \text { at periods } \\
\text { below } 0.2 \mathrm{~s} \\
\text { (frequencies above } 5 \mathrm{~Hz} \text { ). }\end{array}$ \\
\hline
\end{tabular}

by current or emerging technologies. It also demands a dedicated solution for the development of sensing technology to achieve high resolution signal acquisition for passive seismic. This helps in providing better data acquisition and data analysis technique for higher success rate of prediction of hydrocarbon reserves.
The first column of Table 12 shows the sensing type of accelerometers. The bandwidth, acceleration range, and noise floor levels are listed in columns 2-4. Recalling from Section 5 and Table 12, signals required in passive seismic survey are having maximum acceleration of $<80 \mathrm{mg}$ and bandwidth of $1-30 \mathrm{~Hz}$ with $<4 \mathrm{ng} / \sqrt{\mathrm{Hz}}$ noise spectral density 
TABLE 11: Survey based on type of devices used for seismic data acquisition [31].

\begin{tabular}{|c|c|c|c|c|}
\hline Parameters & $\begin{array}{c}\text { Molecular } \\
\text { Electronic } \\
\text { Transducers } \\
\text { (MET) Sensor }\end{array}$ & Geophones & $\begin{array}{c}\text { MEMS } \\
\text { accelerometers }\end{array}$ & Implication \\
\hline Frequency range & $1-500 \mathrm{~Hz}$ & $10-190 \mathrm{~Hz}$ & $\mathrm{DC}-1000 \mathrm{~Hz}$ & $\begin{array}{l}\text { Better imaging of deep, shallow, } \\
\text { and/or narrow layers of deposits }\end{array}$ \\
\hline $\begin{array}{l}\text { Scale factor } \\
\text { stability }\end{array}$ & $<50 \mathrm{ng} / \sqrt{\mathrm{Hz}}$ & * & $500 \mathrm{ng} / \sqrt{\mathrm{Hz}}$ & Higher data quality \\
\hline Sensor noise & Low & Low & Moderate & Higher data quality \\
\hline Sensitivity & High & Low & Low & Longer life in the field \\
\hline Shock tolerance & Very high & Moderate & High & $\begin{array}{c}\text { Usable in a wider range of } \\
\text { surveys }\end{array}$ \\
\hline $\begin{array}{l}\text { Electromagnetic } \\
\text { interference }\end{array}$ & No & Yes & No & $\begin{array}{c}\text { No power line pickup: better data } \\
\text { with less processing required }\end{array}$ \\
\hline Power & Low & Low & High & $\begin{array}{l}\text { Less expensive to operate, longer } \\
\text { battery life }\end{array}$ \\
\hline Cost & Low-med & Low & High & Lower equipment cost \\
\hline
\end{tabular}

TABLE 12: State-of-the-art sensors.

\begin{tabular}{|c|c|c|c|c|}
\hline Sensor & Type & Bandwidth $(\mathrm{Hz})$ & Full scale (mg) & Noise density (ng/rtHz) \\
\hline Trillium T40, T120 [32] & Velocimeter & $0.03-50$ & - & - \\
\hline Geophone accelerometer [23] & Accelerometer & $3-200$ & 108 & 15 \\
\hline DSU1 [18] & Accelerometer & $0-800$ & 500 & $40(>10 \mathrm{~Hz})$ \\
\hline Emerging sensor [33] & Accelerometer & $1-200$ & 80 & 10 \\
\hline
\end{tabular}

TABLE 13: Sensors performance summary [6, 7, 34-39].

\begin{tabular}{lccc}
\hline Type & Bandwidth $(\mathrm{Hz})$ & Acceleration $(\mathrm{g})$ & $\begin{array}{c}\text { Noise density } \\
(\mathrm{g} / \sqrt{\mathrm{Hz}})\end{array}$ \\
\hline Capacitive & $0-30$ & $22 \mu-20 \mathrm{k}$ & $4 \mathrm{n}-357 \mathrm{~m}$ \\
Piezoresistive & $0-35$ & $1-250$ & $100 \mu-500 \mathrm{~m}$ \\
Piezoelectric & $1-60$ & $7-25$ & $10 \mathrm{~m}-110 \mathrm{~m}$ \\
Tunneling & $5-1 \mathrm{k}$ & $1 \mathrm{~m}-30$ & $15 \mathrm{n}-4 \mathrm{~m}$ \\
\hline
\end{tabular}

$[38,40,154,155]$. The data summarized in Table 13 show the superiority of capacitive sensors to meet passive seismic sensing requirements.

\section{Conclusions}

Empirical studies show that the spectral anomalies within the range of $1-30 \mathrm{~Hz}$ are highly correlated to determine the reservoir containing hydrocarbon. The overall study signifies that capacitive sensor is more suitable for meeting the passive seismic sensing requirements with respect to the formation (Table 14). Cost-effective and environmental friendly features of passive seismic technique make it economically viable option.

Thus this paper signifies the sensing technology gap associated with the acquisition of high resolution passive seismic signals which has been discussed to motivate the dedicated solutions for future. However, passive seismic sensors determine a relatively higher cost of installation and also may represent their fragile nature at the low frequency bandwidth below $10 \mathrm{~Hz}$. Therefore, Molecular Electronic Transducers (MTLF-1040) Low Frequency Sensor has been identified as an improved solution of the issues with passive seismic sensors by performing better in the low frequency spectral bandwidth. It also produces a higher sensitivity than conventional seismometers and geophones, with lesser cost estimation. Since it has low output impedance it reduces overdamping which makes its compatible with any devices for passive seismic sensing more accurately.

Overall, the whole study signifies the effectively corrected difference between the active and passive seismic imaging using a novel accelerometer design, such as the following:

(i) Active imaging totally depends on a clear signal-tonoise ration because "noise is bad."

(ii) Passive imaging performs beyond the noise infometry where "noise is good," since it signifies the information carrier and driving force.

Since it is essential to understand that for reservoir response the secondary signal is generated inside the reservoir as the adaptation product which cannot exist before, that means it is considered as original source signal recorded, which cannot be changed and recreated again. Therefore, a passive seismic method potentially offers a wide range of possibilities of recording real source signal with good noise ratio. This may help in determining the accurate information of the reservoir response, reservoir monitoring, and its management effectively. 
TABLE 14

\begin{tabular}{|c|c|c|c|c|c|c|}
\hline $\begin{array}{l}\text { Min. freq. } \\
(\mathrm{Hz})\end{array}$ & $\begin{array}{l}\text { Max. freq. } \\
(\mathrm{Hz})\end{array}$ & $\begin{array}{l}\text { Type of data } \\
\text { acquisition }\end{array}$ & Type of device used & $\begin{array}{l}\text { Type of } \\
\text { reservoir }\end{array}$ & Sensitivity & Analysis \\
\hline 0.0125 & 62.5 & Microseismic & $\begin{array}{c}\text { Hewlett-Packard (HP) } \\
\text { Microelectromechanical } \\
\text { Systems (MEMS) seismic } \\
\text { accelerometer (capacitive } \\
\text { sensor) } \\
{[30]}\end{array}$ & Not specified & $\begin{array}{c}3.3616 E+7 \\
\text { counts/V- } \\
8.4165 E+6 \\
\text { counts/V }\end{array}$ & $\begin{array}{l}\text { The analysis of } \\
\text { self-noise level } \\
\text { signifies } \\
9.8 \mathrm{ng} / \sqrt{\mathrm{Hz}} \text { at } \\
\text { periods below } \\
0.2 \mathrm{~s} \\
\text { (frequencies } \\
\text { above } 5 \mathrm{~Hz} \text { ). }\end{array}$ \\
\hline
\end{tabular}

TABLE 15

\begin{tabular}{|c|c|c|c|c|c|c|}
\hline $\begin{array}{l}\text { Min. freq. } \\
(\mathrm{Hz})\end{array}$ & $\begin{array}{l}\text { Max. freq. } \\
(\mathrm{Hz})\end{array}$ & $\begin{array}{l}\text { Type of data } \\
\text { acquisition }\end{array}$ & $\begin{array}{c}\text { Type of device } \\
\text { used }\end{array}$ & $\begin{array}{l}\text { Type of } \\
\text { reservoir }\end{array}$ & Sensitivity & Analysis \\
\hline 1 & 500 & $\begin{array}{l}\text { Low frequency } \\
\text { passive seismics }\end{array}$ & $\begin{array}{c}\text { Molecular } \\
\text { Electronic } \\
\text { Transducers } \\
\text { (MTLF-1040) } \\
\text { Low Frequency } \\
\text { Sensor } \\
\text { [31] }\end{array}$ & Not specified & High & $\begin{array}{l}\text { (i) Longer life in } \\
\text { the field with } \\
\text { improved } \\
\text { passive seismic } \\
\text { sensing. } \\
\text { (ii) Lesser cost } \\
\text { estimation for } \\
\text { installation. }\end{array}$ \\
\hline
\end{tabular}

TABLE 16: Comparison of existing MEMS accelerometers [30, 36-38, 40].

\begin{tabular}{|c|c|c|c|c|c|c|c|c|}
\hline Manufacturer & Model & Technology & Output & Axis & Sensitivity & Power $(\mathrm{mW})$ & $\begin{array}{c}\text { Acceleration } \\
\text { range }(\mathrm{g})\end{array}$ & $\begin{array}{c}\text { Frequency } \\
\text { response } \\
(\mathrm{Hz})\end{array}$ \\
\hline \multirow{4}{*}{ Colibrys } & SF 1500 & Capacitive & $\mathrm{A}^{*}$ & 1 & $1.2 \mathrm{mv} / \mathrm{g}$ & 100 & \pm 3 & $0-1500$ \\
\hline & SF 2005 & Capacitive & A & 1 & $500 \mathrm{mv} / \mathrm{g}$ & 140 & \pm 4 & $0-1000$ \\
\hline & SF 3000 & Capacitive & A & 3 & $1.2 \mathrm{mv} / \mathrm{g}$ & 200 & \pm 3 & $0-1000$ \\
\hline & Digital 3 & $\begin{array}{l}\text { Capacitive } \\
\text { feedback }\end{array}$ & $\mathrm{D}^{*}$ & 3 & $58 \mathrm{mg} / \mathrm{bit}$ & 780 & \pm 0.2 & 0-1000 \\
\hline \multirow{2}{*}{ Endevco } & 86 & Piezoelectric & $\mathrm{A}$ & 1 & $10 \mathrm{v} / \mathrm{g}$ & 200 & \pm 0.5 & $0.002-200$ \\
\hline & 87 & Piezoelectric & $\mathrm{A}$ & 1 & $10 \mathrm{v} / \mathrm{g}$ & 200 & \pm 0.5 & $0.003-200$ \\
\hline \multirow{2}{*}{ Kinemetrics } & ES-T & Capacitive & $\mathrm{A}$ & 1 & $10 \mathrm{v} / \mathrm{g}$ & 144 & \pm 0.25 & $0-200$ \\
\hline & ESU2 & Capacitive & $\mathrm{A}$ & 3 & $10 \mathrm{v} / \mathrm{g}$ & 100 & \pm 0.25 & $0-200$ \\
\hline Reftek & $131 \mathrm{~A}$ & Capacitive & $\mathrm{A}$ & 3 & $2 \mathrm{v} / \mathrm{g}$ & 600 & \pm 3.5 & $0-400$ \\
\hline \multirow{3}{*}{ Sercel } & DSU1 & Capacitive & $\mathrm{D}$ & 3 & Not specified & 265 & \pm 0.5 & $0-800$ \\
\hline & DSU2 & Capacitive & $\mathrm{D}$ & 3 & Not specified & 265 & \pm 0.5 & $0-800$ \\
\hline & DUS3 & Capacitive & $\mathrm{D}$ & 3 & Not specified & 265 & \pm 0.5 & $0-800$ \\
\hline
\end{tabular}

$\mathrm{A}^{*}=$ analog, $\mathrm{D}^{*}=$ digital.

\section{Appendix}

For more details see Table 16.

\section{Competing Interests}

The authors declare that they have no competing interests.

\section{Acknowledgments}

Atul Kumar sincerely would like to thank the supervisor, Dr. M. H. Md Khir, and cosupervisor, Mr. Wan Ismail Wan
Yusoff, for his exemplary guidance and technical assistance during this study. Atul Kumar also would like to thank Universiti Teknologi PETRONAS for their financial assistance.

\section{References}

[1] A. E. de Vasconcelos Lopes and L. C. Nunes, "Pitfalls of tremorlike signals for hydrocarbon exploration in producing oil fields in Potiguar basin, northeast Brazil," The Leading Edge, vol. 29, no. 7, pp. 826-830, 2010.

[2] S. Dangel, M. E. Schaepman, E. P. Stoll et al., "Phenomenology of tremor-like signals observed over hydrocarbon reservoirs," 
Journal of Volcanology and Geothermal Research, vol. 128, no. 13, pp. 135-158, 2003.

[3] M. A. Gamal, "Using microtremors for microseismic zonation in Cairo's crowded, urban areas," Journal of Seismology, vol. 13, no. 1, pp. 13-30, 2009.

[4] A. Goertz, B. Schechinger, B. Witten, M. Koerbe, and P. Krajewski, "Extracting subsurface information from ambient seismic noise-a case study from Germany," Geophysics, vol. 77, no. 4, pp. KS13-KS31, 2012.

[5] A. Kumar, M. H. M. Khir, and W. I. W. Yusoff, "A model based approach for integration analysis of well log and seismic data for reservoir characterization," Geoscience Journal, pp. 1-20, 2016.

[6] E. V. Birialtsev, E. V. Eronina, D. A. Rizhov, V. A. Rizhov, N. Y. Shabalin, and A. A. Vildanov, "Experience in low-frequency spectral analysis of passive seismic data in volga-ural oil-bearing province," in International Petroleum Technology Conference (IPTC '09), pp. 2095-2105, December 2009.

[7] B. Birkelo, M. Duclos, B. Artman et al., "A passive low-frequency seismic survey in Abu Dhabi-Shaheen project," in Proceedings of the 2010 SEG Annual Meeting, pp. 2207-2211, Denver, Colo, USA, 2010.

[8] N. Riahi, B. Birkelo, and E. H. Saenger, "Analyzing passive seismic attributes: a statistical strategy," in Proceedings of the SEG San Antonio 2011 Annual Meeting, pp. 1688-1692, San Antonio, Tex, USA, 2011.

[9] F. Mohd-Yasin, D. J. Nagel, and C. E. Korman, "Noise in MEMS," Measurement Science and Technology, vol. 21, no. 1, 22 pages, 2010.

[10] T. B. Gabrielson, "Mechanical-thermal noise in micromachined acoustic and vibration sensors," IEEE Transactions on Electron Devices, vol. 40, no. 5, pp. 903-908, 1993.

[11] Z. Djuric, "Mechanisms of noise sources in microelectromechanical systems," Microelectronics Reliability, vol. 40, no. 6, pp. 919-932, 2000.

[12] Z. Djuric, O. Jaksic, and D. Randjelovic, "Adsorption-desorption noise in micromechanical resonant structures," Sensors and Actuators A, vol. 96, no. 2-3, pp. 244-251, 2002.

[13] A. Greiner and J. Korvink, "Extraction of noise parameters for the macro modelling of MEMS," in Proceedings of the International Conference on Advanced Semiconductor Devices and Microsystems, pp. 311-314, 1998.

[14] J. R. Vig and Y. Kim, "Noise in microelectromechanical system resonators," IEEE Transactions on Ultrasonics, Ferroelectrics, and Frequency Control, vol. 46, no. 6, pp. 1558-1565, 1999.

[15] R. P. Leland, "Mechanical-thermal noise in MEMS gyroscopes," IEEE Sensors Journal, vol. 5, no. 3, pp. 493-500, 2005.

[16] J. Laine and D. Mougenot, "Benefits of MEMS based seismic accelerometers for oil exploration," in Proceedings of the International Solid-State Sensors, Actuators and Microsystems Conference (TRANSDUCERS '07), pp. 1473-1477, IEEE, Lyon, France, June 2007.

[17] WesternGeco, "UniQ integrated point-receiver land seismic system: ground equipement," Technical Specifications, WesternGeco, Crawley, UK, 2012.

[18] D. Mougenot and A. Cherepovskiy, "DSU1: a single sensor that makes sense," Digital Sensor Unit-1, Sercel, pp. 1-2, 2011.

[19] D. J. Milligan, B. D. Homeijer, and R. G. Walmsley, "An ultra-low noise MEMS accelerometer for seismic imaging," in Proceedings of the IEEE Sensors, pp. 1281-1284, Limerick, Ireland, October 2011.
[20] Nanometrics, Trillium 40 Seismometer User Guide, Nanometrics, Milpitas, Calif, USA, 2009.

[21] R. Holzner, P. Eschle, M. Frehner, S. Schmalholz, and Y. Podladchikov, "Interpretation of hydrocarbon microtremors as nonlinear oscillations driven by oceanic background waves," in Proceedings of the SEG Annual Meeting, pp. 2294-2298, SEG, New Orleans, La, USA, 2006.

[22] E. H. Saenger, S. M. Schmalholz, M.-A. Lambert et al., "A passive seismic survey over a gas field: analysis of low-frequency anomalies," Geophysics, vol. 74, no. 2, pp. O29-O40, 2009.

[23] WesternGeco, "UniQ integrated point-receiver land seismic system: ground equipment," Technical Specifications, WesternGeco, Crawley, UK, 2012.

[24] F. Martini, I. Lokmer, K. Jonsdottir et al., "A passive lowfrequency seismic experiment in the Albertine Graben, Uganda," Geophysical Prospecting, vol. 61, supplement 1, pp. 39-61, 2013.

[25] S. Molnar, J. Cassidy, P. Monahan, and T. Onur, "Earthquake site response studies using microtremor measurements in southwestern British Columbia," in Proceedings of the 9th Canadian Conference on Earthquake Engineering, pp. 410-419, 2007.

[26] D. J. Milligan, B. D. Hom, and R. G. Walmsley, "An ultra-low noise MEMS accelerometer for seismic imaging," in Proccedings of the IEEE Sensors, pp. 1281-1284, Limerick, Ireland, October 2011.

[27] J. F. Tan, R. R. Stewart, and J. Wong, "Classification of microseismic events via principal component analysis of trace statistics," Crewes Research Reports, pp. 1-11, 2009.

[28] S. Sarkar, H. Sadi Kuleli, M. Nafi Toksöz et al., "Eight years of passive seismic monitoring at a petroleum field in Oman: a case study," SEG Technical Program Expanded Abstracts, pp. 13971401, 2008.

[29] M. Y. Ali, K. A. Berteussen, J. Small, and B. Barkat, "Lowfrequency passive seismic experiments in Abu Dhabi, United Arab Emirates: implications for hydrocarbon detection," Geophysical Prospecting, vol. 58, no. 5, pp. 875-899, 2010.

[30] B. D. Homeijer, D. J. Milligan, and C. R. Hutt, "A brief test of the hewlett-packard mems seismic accelerometer," U.S. Geological Survey Open-File Report 2014-1047, 2014.

[31] Geophysics Internal Sensors, METTech, http://mettechnology .com/Products/MTLF1040.pdf.

[32] J. Thorbecke and K. Wapenaar, "Analysis of spurious events in seismic interferometry," SEG Technical Program Expanded Abstracts, vol. 27, no. 1, pp. 1415-1420, 2008.

[33] "Lecture note on 'Assessing MEMS Accelerometers Performance,' MEM224 Experimental Engineering, Northwestern University, 2006.

[34] A. Ahanchian and B. Y. Majlis, "Simulation of an analog differential capacitive accelerometer," in Proceedings of the IEEE International Conference on Semiconductor Electronics (ICSE '04), pp. 331-334, December 2004.

[35] G. L. Pavlis, "Imaging the earth with passive seismic arrays," The Leading Edge, vol. 22, no. 3, pp. 224-231, 2003.

[36] K. Wapenaar, J. van der Neut, and E. Ruigrok, "Passive seismic interferometry by multidimensional deconvolution," Geophysics, vol. 73, no. 6, pp. A51-A56, 2008.

[37] S. Wilson, R. Jones, W. Wason, D. Raymer, and P. Jaques, "Passive seismic makes sense for 4 D reservoir monitoring," First Break, vol. 22, no. 10, pp. 59-65, 2004.

[38] Nanometrics, Trillium 40 Seismometer User Guide, Nanometrics, Ottawa, Canada, 2009. 
[39] C. Bland Henry, "An analysis of passive seismic recording performance," Crewes Research Reports, vol. 18, pp. 1-9, 2006.

[40] B. J. Merchant, "MEMS applications in seismology," in Proceedings of the Seismic Instrumentation Technology Symposium, Sandia National Laboratory, 2009.

[41] S. I. Kaka, "Passive microseismic experiments at King Fahd University of Petroleum and Minerals in Saudi Arabia," Seismological Research Letters, vol. 83, no. 4, pp. 680-685, 2012.

[42] A. Kannan, Design and modeling of a MEMS-based accelerometer with pull in analysis [M.S. thesis], The University of British Columbia, 2008.

[43] M. Haris and H. Qu, "A CMOS-MEMS piezoresistive accelerometer with large proof mass," in Proceedings of the 5th IEEE International Conference on Nano/Micro Engineered and Molecular Systems (NEMS '10), pp. 309-312, Xiamen, China, January 2010.

[44] S. Beißner, M. Puppich, S. Bütefisch, S. Büttgenbach, and T. Elbel, "Analog force feedback circuit for capacitive micromechanical acceleration sensors," in Proceedings of the Sensors, May 2001.

[45] K. Zhang, Sensing and control of MEMS accelerometers using Kalman filter [M.S. thesis], Cleveland State University, Cleveland, Ohio, USA, 2010.

[46] H. Qu, D. Fang, and H. Xie, "A monolithic CMOS-MEMS 3axis accelerometer with a low-noise, low-power dual-chopper amplifier," IEEE Sensors Journal, vol. 8, no. 9, pp. 1511-1518, 2008.

[47] Q. Zou, W. Tan, E. S. Kim, and G. E. Loeb, "Single- and triaxis piezoelectric-bimorph accelerometers," Journal of Microelectromechanical Systems, vol. 17, no. 1, pp. 45-57, 2008.

[48] T. Cui and J. Wang, "Polymer-based wide-bandwidth and highsensitivity micromachined electron tunneling accelerometers using hot embossing," Journal of Microelectromechanical Systems, vol. 14, no. 5, pp. 895-902, 2005.

[49] S. Chen, C. Xue, W. Zhang, J. Xiong, B. Zhang, and J. Hu, "A new type of MEMS two axis accelerometer based on silicon," in Proceedings of the 3rd IEEE International Conference on Nano/Micro Engineered and Molecular Systems (NEMS '08), pp. 959-964, Sanya, China, January 2008.

[50] S. Beepy, G. Ensell, M. Kraft, and N. White, MEMS Mechanical Sensors, Artech House, Norwood, Mass, USA, 2004.

[51] A. A. Barlian, W.-T. Park, J. R. Mallon Jr., A. J. Rastegar, and B. L. Pruitt, "Review: semiconductor piezoresistance for microsystems," Proceedings of the IEEE, vol. 97, no. 3, pp. 513552,2009

[52] D. V. Dao, S. Okada, T. Van Dau, T. Toriyama, and S. Sugiyama, "Development of a 3-DOF silicon piezoresistive micro accelerometer," in Proceedings of the International Symposium on Micro-NanoMecahtronics and Human Science and the 4th Symposium Micro-NanoMechatronics for and InformationBased Society, vol. 2004, pp. 1-6, November 2004.

[53] A. Partridge, J. K. Reynolds, B. W. Chui et al., "A highperformance planar piezoresistive accelerometer," Journal of Microelectromechanical Systems, vol. 9, no. 1, pp. 58-66, 2000.

[54] N. Yazdi, F. Ayazi, and K. Najafi, "Micromachined inertial sensors," Proceedings of the IEEE, vol. 86, no. 8, pp. 1640-1658, 1998.

[55] S. Huang, X. Li, Y. Wang et al., "A piezoresistive accelerometer with axially stressed tiny beams for both much," in Proceedings of the 12th International Conference on Solid State Sensors, Actuators and Microsystems, pp. 91-94, Boston, Mass, USA, June 2003.
[56] W.-T. Park, A. Partridge, R. N. Candler et al., "Encapsulated submillimeter piezoresistive accelerometers," Journal of Microelectromechanical Systems, vol. 15, no. 3, pp. 507-514, 2006.

[57] A. Chaehoi, L. Latorre, P. Nouet, and S. Baglio, "Piezoresistive CMOS beams for inertial sensing," in Proceedings of the IEEE Sensors Conference, pp. 451-456, October 2003.

[58] R. Amarasinghe, D. V. Dao, T. Toriyama, and S. Sugiyama, "A silicon micromachined six-degree of freedom piezoresistive accelerometer," in Proceedings of the IEEE Sensors, vol. 2, pp. 852-855, October 2004.

[59] E. Gallasch, D. Rafolt, M. Moser et al., "Instrumentation for assessment of tremor, skin vibrations, and cardiovascular variables in MIR space missions," IEEE Transactions on Biomedical Engineering, vol. 43, no. 3, pp. 328-333, 1996.

[60] R. Amarasinghe, D. V. Dao, and S. Sugiyama, "Ultra miniature $\mu$-accelerometer for wearable physical activity monitoring systems," in Proceedings of the International Symposium on MicroNanoMechatronics and Human Science (MHS '09), pp. 467-471, IEEE, Nagoya, Japan, November 2009.

[61] M. Messina, J. Njuguna, V. Dariol, C. Pace, and G. Angeletti, "Design and simulation of a novel biomechanic piezoresistive sensor with silicon nanowires," IEEE/ASME Transactions on Mechatronics, vol. 18, no. 3, pp. 1201-1210, 2013.

[62] Q. Zou, W. Tan, E. S. Kim, and G. E. Loeb, "Highly symmetric tri-axis piezoelectric bimorph accelerometer," in Proceedings of the 17th IEEE International Conference on Micro Electro Mechanical Systems (MEMS '04), pp. 197-200, January 2004.

[63] S. Chen, C. Xue, B. Zhang, B. Xie, and H. Qiao, "A novel MEMS based piezoresistive vector hydrophone for low frequency detection," in Proceedings of the IEEE International Conference on Mechatronics and Automation (ICMA '07), pp. 1839-1844, IEEE, Harbin, China, August 2007.

[64] P. Robert, V. Nguyen, S. Hentz et al., "M\&NEMS: a new approach for ultra-low cost 3D inertial sensor," in Proceedings of the IEEE Conference on Sensors (SENSORS '09), pp. 963-966, October 2009.

[65] M. Lemkin and B. E. Boser, "Micromachined fully differential lateral accelerometer," in Proceedings of the IEEE Custom Integrated Circuits Conference, pp. 315-318, May 1996.

[66] A. Selvakumar, F. Ayazi, and K. Najafi, "A high sensitivity Z-axis torsional silicon accelerometer," in Proceedings of the International Electron Devices Meeting, pp. 765-768, IEEE, San Francisco, Calif, USA, 1996.

[67] J. C. Lotters, W. Olthuis, P. H. Veltink, and P. Bergveld, "Theory, technology and assembly of a highly symmetrical capacitive triaxial accelerometer," in Proceedings of the 10th Annual International Workshop on Micro Electro Mechanical Systems (MEMS '97), pp. 31-36, January 1997.

[68] J. C. Lotters, W. Olthuis, P. H. Veltink, and P. Bergveld, "Characterisation of a highly symmetrical miniature capacitive triaxial accelerometer," in Proceedings of the International Conference on Solid State Sensors and Actuators (TRANSDUCERS '97), pp. 1177-1180, Chicago, Ill, USA, June 1997.

[69] A. Selvakumar and K. Najafi, "A high-sensitivity Z-axis capacitive silicon microaccelerometer with a torsional suspension," Journal of Microelectromechanical Systems, vol. 7, no. 2, pp. 192200, 1998.

[70] K. Y. Park, C. W. Lee, H. S. Jang, Y. S. Oh, and B. J. Ha, “Capacitive sensing type surface micromachined silicon accelerometer with a stiffness tuning capability," in Proceedings of the 11th Annual International Workshop on Micro Electro Mechanical Systems, pp. 637-642, January 1998. 
[71] H. Hamacher, H.-E. Richter, and S. Drees, "A system to measure absolute low frequency acceleration on the International Space Station," in Proceedings of the 16th IEEE Instrumentation and Measurement Technology Conference (IMTC'99), vol. 1, pp. 249253, Venice, Italy, May 1999, Cat. No.99CH36309.

[72] J. Bernstein, R. Miller, W. Kelley, and P. Ward, "Low-noise MEMS vibration sensor for geophysical applications," Journal of Microelectromechanical Systems, vol. 8, no. 4, pp. 433-438, 1999.

[73] H. Takao, Y. Matsumoto, and M. Ishida, "A monolithically integrated three-axis accelerometer using CMOS compatible stress-sensitive differential amplifiers," IEEE Transactions on Electron Devices, vol. 46, no. 1, pp. 109-116, 1999.

[74] N. Yazdi and K. Najafi, "All-silicon single-wafer micro-g accelerometer with a combined surface and bulk micromachining process," Journal of Microelectromechanical Systems, vol. 9, no. 4, pp. 544-550, 2000.

[75] H. Xie and G. K. Fedder, "CMOS z-axis capacitive accelerometer with comb-finger sensing," in Proceedings of the 13th Annual International Conference on Micro Electro Mechanical Systems (MEMS '00), pp. 496-501, Miyazaki, Japan, January 2000.

[76] H. Takao, H. Fukumoto, and M. Ishida, "Fabrication of a three-axis accelerometer integrated with commercial $0.8 \mu \mathrm{m}$ CMOS circuits," in Proceedings of the 13th Annual International Conference on Micro Electro Mechanical Systems (MEMS '00), pp. 781-786, IEEE, Miyazaki, Japan, January 2000.

[77] V. Biefeld, B. Clasbrummel, and J. Binder, "Implantable low$\mathrm{g}$ accelerometer for the telemetric monitoring of micromovements in fracture zones," in Proceedings of the 1st Annual International IEEE-EMBS Special Topic Conference on Microtechnologies in Medicine and Biology, pp. 497-501, Lyon, France, 2000.

[78] J. Chae, H. Kulah, and K. Najafi, "A monolithic three-axis silicon capacitive accelerometer with micro-g resolution," in Proceedings of the 12th International Conference on Solid-State Sensors, Actuators and Microsystems (TRANSDUCERS '03), pp. 81-84, June 2003.

[79] B. Quintal, S. M. Schmalholz, and Y. Y. Podladchikov, "Lowfrequency reflections from a thin layer with high attenuation caused by interlayer flow," Geophysics, vol. 74, no. 1, pp. N15N23, 2009.

[80] H. Kulah, J. Chae, and K. Najafi, "Noise analysis and characterization of a sigma-delta capacitive silicon microaccelerometer," in Proceedings of the 12th International Conference on Solid-State Sensors, Actuators and Microsystems (TRANSDUCERS '03), vol. 1, pp. 95-98, IEEE, Boston, Mass, USA, June 2003.

[81] J. Chae, H. Kulah, and K. Najafi, "An in-plane high-sensitivity, low-noise micro-g silicon accelerometer," in Proceedings of the IEEE 16th Annual International Conference on Micro Electro Mechanical Systems, pp. 466-469, Kyoto, Japan, January 2003.

[82] B. V. Amini and F. Ayazi, "A 2.5-V 14-bit $\sum \Delta$ CMOS SOI capacitive accelerometer," IEEE Journal of Solid-State Circuits, vol. 39, no. 12, pp. 2467-2476, 2004.

[83] J. Chae, H. Kulah, and K. Najafi, "An in-plane high-sensitivity, low-noise micro-g silicon accelerometer with CMOS readout circuitry," Journal of Microelectromechanical Systems, vol. 13, no. 4, pp. 628-635, 2004.

[84] B. V. Amini, S. Pourkamali, and F. Ayazi, "A high resolution, stictionless, cmos compatible soi accelerometer with a Low noise, Low power, $0.25 \mu \mathrm{M}$ cmos interface," in Proceedings of the17th IEEE International Conference on Micro Electro Mechanical Systems (MEMS '04), pp. 572-575, January 2004.
[85] J. Chae, H. Kulah, and K. Najafi, "A monolithic three-axis microg micromachined silicon capacitive accelerometer," Journal of Microelectromechanical Systems, vol. 14, no. 2, pp. 235-242, 2005.

[86] A. Sadat, H. Qu, C. Yu, J. S. Yuan, and H. Xie, "Low-power CMOS wireless MEMS motion sensor for physiological activity monitoring," IEEE Transactions on Circuits and Systems I: Regular Papers, vol. 52, no. 12, pp. 2539-2551, 2005.

[87] P. Monajemi and F. Ayazi, "Design optimization and implementation of a microgravity capacitive HARPSS accelerometer," IEEE Sensors Journal, vol. 6, no. 1, pp. 39-46, 2006.

[88] Y. S. Suzuki and Y.-C. Tai, "Micromachined high-aspect-ratio parylene spring and its application to low-frequency accelerometers," Journal of Microelectromechanical Systems, vol. 15, no. 5, pp. 1364-1370, 2006.

[89] R. Abdolvand, B. V. Amini, and F. Ayazi, "Sub-micro-gravity in-plane accelerometers with reduced capacitive gaps and extra seismic mass," Journal of Microelectromechanical Systems, vol. 16, no. 5, pp. 1036-1043, 2007.

[90] Y. W. Hsu, H. T. Chien, C. S. Lin, L. P. Liao, S. Chen, and P. Chang, "A capacitive low-g three-axis accelerometer," in Proceedings of the 10th International Conference on Electronic Materials and Packaging (EMAP'08), pp. 325-328, IEEE, Taipei, Taiwan, October 2008.

[91] R. Kepenek, I. E. Ocak, H. Kulah, and T. Akin, "A $\mu$ g resolution microacelerometer system with a second-order $\Sigma-\Delta$ readout circuitry," in Proceedings of the Research in Microelectronics and Electronics (PRIME '08), pp. 41-44, Istanbul, Turkey.

[92] A. Wung, R. V. Park, K. J. Rebello, and G. K. Fedder, "Triaxial high-G CMOS-MEMS capacitive accelerometer array," in Proceedings of the 21st IEEE International Conference on Micro Electro Mechanical Systems (MEMS '08), pp. 876-879, January 2008.

[93] W. T. Pike, I. M. Standley, W. J. Karl et al., "Design, fabrication and testing of a micromachined seismometer with NANO-G resolution," in Proceedings of the 15th International Conference on Solid-State Sensors, Actuators and Microsystems (TRANSDUCERS '09), pp. 668-671, Denver, Colo, USA, June 2009.

[94] R. G. Walmsley, L. K. Kiyama, D. M. Milligan, R. L. Alley, D. L. Erickson, and P. G. Hartwell, "Micro-G silicon accelerometer using surface electrodes," in Proceedings of the IEEE Conference on Sensors (SENSORS '09), pp. 971-974, October 2009.

[95] B. Boga, I. E. Ocak, H. Kulah, and T. Akin, "Modeling of a capacitive $\sum-\delta$ MEMS accelerometer system including the noise components and verification with test results," in Proceedings of the 22nd IEEE International Conference on Micro Electro Mechanical Systems (MEMS '09), pp. 821-824, January 2009.

[96] D. Hollocher, X. Zhang, A. Sparks et al., "A very low cost, 3-axis, MEMS accelerometer for consumer applications," in Proceedings of the IEEE Sensors, pp. 953-957, Christchurch, New Zealand, October 2009.

[97] Y. Hsu, S. Lin, and C. Lin, "A low-g three-axis accelerometer IC," in Proceedings of the 4th International Microsystems, Packaging, Assembly and Circuits Technology Conference, pp. 319-322, IEEE, Taipei, Taiwan, 2009.

[98] L. Novak, P. Neuzil, J. Li, and M. Woo, "Ultrasensitive MEMSbased inertial system," in Proceedings of the IEEE Conference on Sensors (SENSORS '09), pp. 552-554, October 2009.

[99] Y. Li, L. Wang, and J. Liu, "Capacitive silicon microaccelerometer detecting technology research," in Proceedings of the International Conference on Measuring Technology and 
Mechatronics Automation (ICMTMA '09), pp. 186-189, Zhangjiajie, China, April 2009.

[100] Y. Hirata, N. Konno, T. Tokunaga, M. Tsugai, and H. Fukumoto, "A new z-axis capacitive accelerometer with high impact durability," in Proceedings of the 15th International Conference on Solid-State Sensors, Actuators and Microsystems (TRANSDUCERS '09), pp. 1158-1161, Denver, Colo, USA, June 2009.

[101] P. Zwahlen, A.-M. Nguyen, Y. Dong, F. Rudolf, M. Pastre, and H. Schmid, "Navigation grade MEMS accelerometer," in Proceedings of the 23rd IEEE International Conference on Micro Electro Mechanical Systems (MEMS '10), pp. 631-634, Hong Kong, January 2010.

[102] S. S. Tan, C. Y. Liu, L. K. Yeh, Y. H. Chiu, M. S.-C. Lu, and K. Y. J. Hsu, "Design of low-noise CMOS MEMS accelerometer with techniques for thermal stability and stable DC biasing," in Proceedings of the 32nd Annual Custom Integrated Circuits Conference (CICC '10), pp. 1-4, San Jose, Calif, USA, September 2010.

[103] C.-M. Sun, M.-H. Tsai, Y.-C. Liu, and W. Fang, "Implementation of a monolithic single proof-mass tri-axis accelerometer using CMOS-MEMS technique," IEEE Transactions on Electron Devices, vol. 57, no. 7, pp. 1670-1679, 2010.

[104] C. H. Je, S. Lee, M. L. Lee, J. Lee, W. S. Yang, and C. A. Choi, "Z-axis capacitive MEMS accelerometer with moving ground masses," in Proceedings of the IEEE Sensors, pp. 635-638, IEEE, Kona, Hawaii, USA, November 2010.

[105] B. Homeijer, D. Lazaroff, D. Milligan et al., "Hewlett packard's seismic grade MEMS accelerometer," in Proceedings of the 24th IEEE International Conference on Micro Electro Mechanical Systems (MEMS '11), pp. 585-588, Cancun, Mexico, January 2011.

[106] Y. Dong, P. Zwahlen, A. M. Nguyen, R. Frosio, and F. Rudolf, "Ultra-high precision MEMS accelerometer closed-loop system design," in Proceedings of the International Solid-State Sensors, Actuators and Microsystems Conference (Transducers '11), pp. 695-698, Beijing, China, 2011.

[107] Q. Hu, C. Gao, Y. Zhang, J. Cui, and Y. Hao, "Design of a novel low cross-axis sensitivity micro-gravity sandwich capacitance accelerometer," in Proceedings of the 6th IEEE International Conference on Nano/Micro Engineered and Molecular Systems (NEMS '11), pp. 642-645, IEEE, Kaohsiung, Taiwan, February 2011.

[108] U. Sonmez, H. Kulah, and T. Akin, "A fourth order unconstrained $\sum \Delta$ capacitive accelerometer," in Proceedings of the 16th International Solid-State Sensors, Actuators and Microsystems Conference (TRANSDUCERS '11), pp. 707-710, June 2011.

[109] I. E. Gönenli, Z. Çelik-Butler, and D. P. Butler, "Surface micromachined MEMS accelerometers on flexible polyimide substrate," IEEE Sensors Journal, vol. 11, no. 10, pp. 2318-2326, 2011.

[110] Q. Hu, C. Gao, Y. Hao, Y. Zhang, and G. Yang, "Low crossaxis sensitivity micro-gravity microelectromechanical system sandwich capacitance accelerometer," Micro and Nano Letters, vol. 6, no. 7, pp. 510-514, 2011.

[111] D. J. Young, M. A. Zurcher, M. Semaan, C. A. Megerian, and W. H. Ko, "MEMS capacitive accelerometer-based middle ear microphone," IEEE Transactions on Biomedical Engineering, vol. 59, no. 12, pp. 3283-3292, 2012.

[112] J. Wang, Z. Yang, and G. Yan, "A silicon-on-glass Z-axis accelerometer with vertical sensing comb capacitors," in Proceedings of the 7th IEEE International Conference on Nano/Micro
Engineered and Molecular Systems (NEMS '12), pp. 583-586, Kyoto, Japan, March 2012.

[113] F. Garcia, E. L. Hixson, C. I. Huerta, and H. Orozco, "Seismic accelerometer," in Proceedings of the 16th IEEE Instrumentation and Measurement Technology Conference (IMTC '99), vol. 3, pp. 1342-1346, Venice, Italy, May 1999, Cat. No.99CH36309.

[114] L.-P. Wang, K. Deng, L. Zou, R. Wolf, R. J. Davis, and S. Trolier-McKinstry, "Microelectromechanical systems (MEMS) accelerometers using lead zirconate titanate thick films," IEEE Electron Device Letters, vol. 23, no. 4, pp. 182-184, 2002.

[115] L.-P. Wang, R. A. Wolf Jr., Y. Wang et al., "Design, fabrication, and measurement of high-sensitivity piezoelectric microelectromechanical systems accelerometers," Journal of Microelectromechanical Systems, vol. 12, no. 4, pp. 433-439, 2003.

[116] F. Gerfers, M. Kohlstadt, H. Bar, M.-Y. He, Y. Manoli, and L.-P. Wang, "Sub- $\mu$ g ultra-low-noise MEMS accelerometers based on CMOS-compatible piezoelectric AIN thin films," in Proceedings of the 4th International Conference on SolidState Sensors, Actuators and Microsystems (TRANSDUCERS and EUROSENSORS '07), pp. 1191-1194, June 2007.

[117] Y. Hu and Y. Xu, "An ultra-sensitive wearable accelerometer for continuous heart and lung sound monitoring," in Proceedings of the Annual International Conference of the IEEE Engineering in Medicine and Biology Society (EMBS '12), pp. 694-697, IEEE, San Diego, Calif, USA, September 2012.

[118] F. A. Levinzon, "Fundamental noise limit of piezoelectric accelerometer," IEEE Sensors Journal, vol. 4, no. 1, pp. 108-111, 2004.

[119] C. Yeh and K. Najafi, "A low-voltage tunneling-based silicon microaccelerometer," IEEE Transactions on Electron Devices, vol. 44, no. 11, pp. 1875-1882, 1997.

[120] C. Yeh and K. Najafi, "Micromachined tunneling accelerometer with a low-voltage CMOS interface circuit," in Proceedings of the International Solid State Sensors and Actuators Conference (Transducers '97), vol. 2, pp. 1213-1216, 1997.

[121] C.-H. Liu and T. W. Kenny, "A high-precision, wide-bandwidth micromachined tunneling accelerometer," Journal of Microelectromechanical Systems, vol. 10, no. 3, pp. 425-433, 2001.

[122] L. Novak, P. Neuzil, J. Li, and M. Woo, "Ultrasensitive MEMSbased inertial system," in Proceedings of the IEEE Sensors, pp. 552-554, Christchurch, New Zealand, October 2009.

[123] Z. Zhang, J. Wu, S. Bernard, and R. G. Walmsley, "Chip on Board development for a novel MEMS accelerometer for seismic imaging," in Proceedings of the IEEE 62nd Electronic Components and Technology Conference (ECTC '12), pp. 350355, San Diego, Calif, USA, June 2012.

[124] H. Qu, Development of DRIE CMOS-MEMS Process and Integrated Accelerometers, University of Florida, Gainesville, Fla, USA, 2006.

[125] W. Kuehnel, "Modelling of the mechanical behaviour of a differential capacitor acceleration sensor," Sensors and Actuators A: Physical, vol. 48, no. 2, pp. 101-108, 1995.

[126] K. T. V. Grattan and T. Sun, "Fiber optic sensor technology: an overview," Sensors and Actuators A: Physical, vol. 82, no. 1, pp. 40-61, 2000.

[127] S. Elies and S. Ebenhoch, "Performance analysis of commercial accelerometers of different technologies," in Proceedings of the 16th International Conference on Sensor Device Technologies and Applications, pp. 54-59, Venice, Italy, August 2015.

[128] J. Fennelly, S. Ding, J. Newton, and Y. Zhao, "Thermal MEMS accelerometers fit many applications," Sensor Magazin, pp. 18$20,2012$. 
[129] G. Koc and K. Yegin, "Hardware design of seismic sensors in wireless sensor network," International Journal of Distributed Sensor Networks, vol. 2013, Article ID 640692, 8 pages, 2013.

[130] G. M. Goloshubin, V. A. Korneev, M. Vjacheslav, and M. Vingalov, "Seismic low-frequency effects from oil-saturated reservoir zones," in Proceedings of the SEG International Exposition and 72nd Annual Meeting, pp. 1-4, 2002.

[131] B. J. Merchant, "MEMS applications in seismology," in Proceedings of the Seismic Instrumentation Technology Symposium, Sandia National Laboratory, November 2009.

[132] S. A. Shapiro, M. Parotidis, S. Rentsch, and E. Rothert, "Reservoir characterization using passive seismic monitoring: physical fundamentals and road ahead," in Proceedings of the SEG International Exposition and 74th Annual Meeting, vol. 4, pp. 14, 2004.

[133] N. Martin and R. R. Stewart, "The effect of low frequencies on seismic analysis," CREWES Research Report, vol. 6, pp. 1-8, 1994.

[134] M. Warner, A. Ratcliffe, T. Nangoo et al., "Anisotropic 3D fullwaveform inversion," Geophysics, vol. 78, no. 2, pp. R59-R80, 2013.

[135] G. Goloshubin, C. Van Schuyver, V. Korneev, D. Silin, and V. Vingalov, "Reservoir imaging using low frequencies of seismic reflections," The Leading Edge, vol. 25, no. 5, pp. 527-531, 2006.

[136] A. J. Berkhout, Seismic Migration Imaging of Acoustic Energy by Wave Field Extrapolation A. Theoretical Aspects, vol. 14 of Developments in Solid Earth Geophysics, 2nd edition, 1982.

[137] C. J. Beasley, R. E. Chambers, and Z. Jiang, "A new look at simultaneous sources," in Proceedings of the 68th Annual International Meeting, SEG, Expanded Abstracts, vol. 17, pp. 133135, 1998.

[138] J. Stefani, G. Hampson, and E. F. Herkenhoff, "Acquisition using simultaneous sources," in Proceedings of the 69th Conference \& Exhibition EAGE Expanded Abstracts, vol. 27, no. 7, pp. 918-923, 2007.

[139] A. J. Berkhout and C. P. A. Wapenaar, "A unified approach to acoustical reflection imaging. II: the inverse problem," The Journal of the Acoustical Society of America, vol. 93, no. 4, pp. 2017-2023, 1993.

[140] A. J. Berkhout, "Changing the mindset in seismic data acquisition," The Leading Edge, vol. 27, no. 7, pp. 924-938, 2008.

[141] L. T. Ikelle, "Coding and decoding: seismic data modeling, acquisition and processing," in Proceedings of the 77th Annual Meeting, SEG, Expanded Abstracts, vol. 26, pp. 64-67, San Antonio, Tex, USA, September 2007.

[142] D. Draganov, K. Wapenaar, and J. W. Thorbecke, "Seismic interferometry: reconstructing the Earth's reflection response," Geophysics, vol. 71, no. 4, pp. SI61-SI70, 2006.

[143] P. Duncan, "Is there a future for passive seismic?" First Break, vol. 23, pp. 111-117, 2005.

[144] S. Dangel, M. E. Schaepman, E. P. Stoll et al., "Phenomenology of tremor-like signals observed over hydrocarbon reservoirs," Journal of Volcanology and Geothermal Research, vol. 128, no. 13, pp. 135-158, 2003.

[145] K. Akrawi and G. Bloch, "Application of passive seismic (IPDS) surveys in Arabian Peninsula," in Proceedings of the EAGE Workshop on Passive Seismic, Exploration and Monitoring Applications, Dubai, UAE, December 2006.

[146] E. V. Birialtsev, I. N. Plotnikova, I. R. Khabibulin, and N. Y. Shabalin, "The analysis of microseisms spectrum at prospecting of oil reservoir on republic tatarstan," in Proceedings of the 68th International Conference and Exhibition (EAGE '06), October 2006.
[147] R. Graf, S. M. Schmalholz, Y. Podladchikov, and E. H. Saenger, "Passive low frequency spectral analysis: exploring a new field in geophysics," World Oil, vol. 228, no. 1, pp. 47-52, 2007.

[148] M.-A. Lambert, S. M. Schmalholz, E. H. Saenger, and B. Steiner, "Low-frequency microtremor anomalies at an oil and gas field in Voitsdorf, Austria," Geophysical Prospecting, vol. 57, no. 3, pp. 393-411, 2009.

[149] G. R. Rached, "Surface passive seismic in Kuwait," in Proceedings of the EAGE Workshop on Passive Seismic: Exploration and Monitoring Applications, vol. A27, December 2006.

[150] A. E. Suntsov, S. L. Aroutunov, A. M. Mekhnin, and B. Y. Meltchouk, "Passive infra-frequency microseismic technology-experience and problems of practical use," in Proceedings of the EAGE Workshop on Passive Seismic, Exploration and Monitoring Applications, article A25, Dubai, UAE, December 2006.

[151] P. Van Mastrigt and A. Al-Dulaijan, "Seismic spectroscopy using amplified 3-C geophones," in Proceedings of the 70th International Conference and Exhibition, EAGE, Extended Abstracts, B047, 2008.

[152] http://www.aapg.org/explorer/2007/06jun/passive_seismic.cfm.

[153] A. Albarbar, A. Badri, J. K. Sinha, and A. Starr, "Performance evaluation of MEMS accelerometers," Measurement, vol. 42, no. 5, pp. 790-795, 2009.

[154] M. Peter and M. Lansley, "What receivers will we use for low frequencies?" in Proceedings of the SEG San Antonio Annual Meeting, pp. 72-76, 2011.

[155] E. V. Egorov, I. V. Egorov, and V. M. Agafonov, "Self-Noise of the MET angular motion seismic sensors," Journal of Sensors, vol. 2015, Article ID 512645, 5 pages, 2015. 


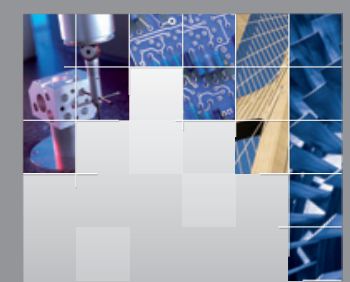

\section{Enfincering}
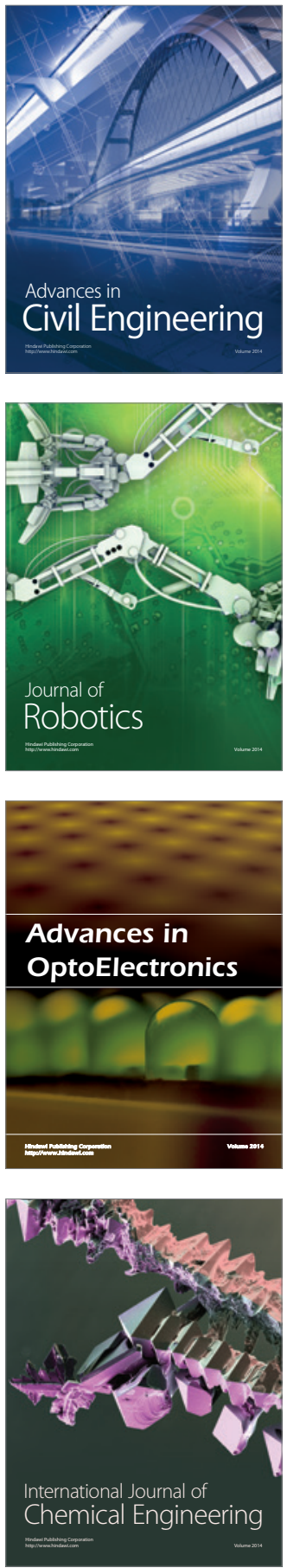

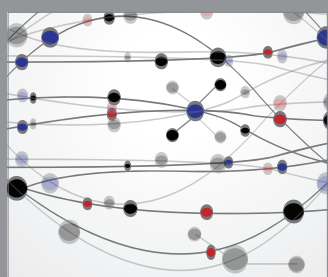

The Scientific World Journal

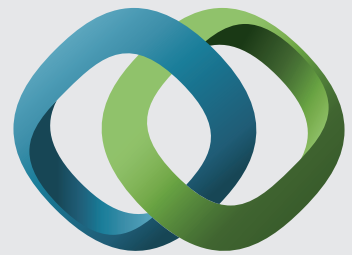

\section{Hindawi}

Submit your manuscripts at

http://www.hindawi.com
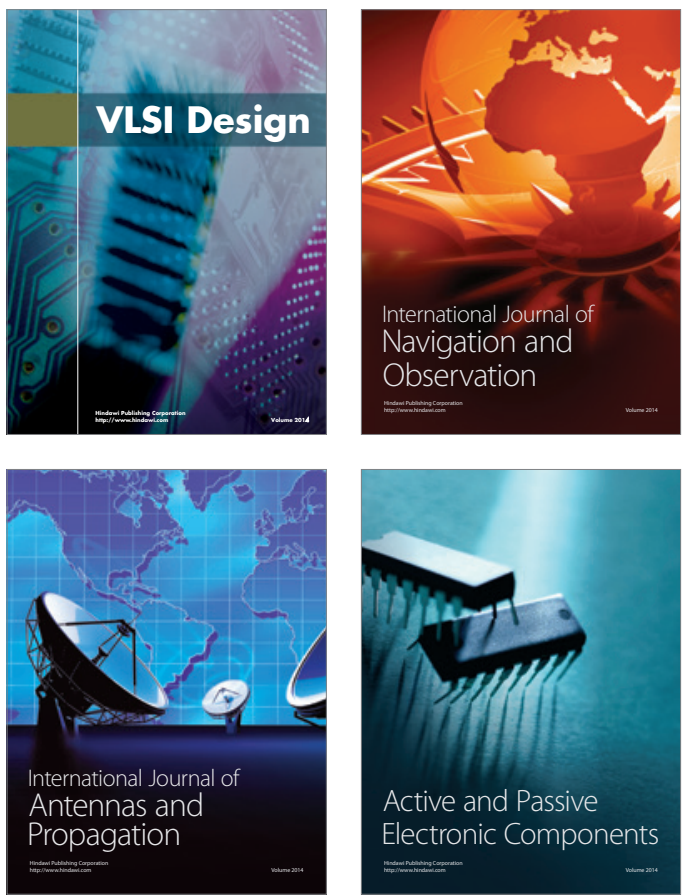
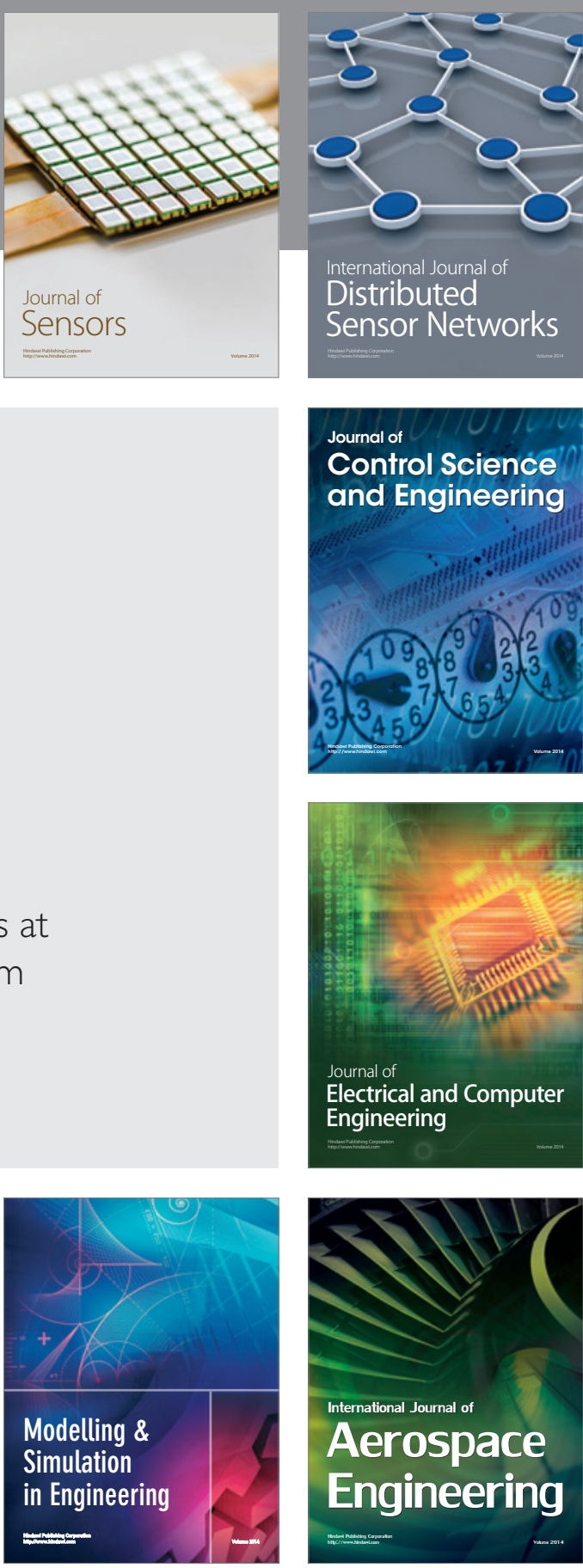

International Journal of

Distributed

Sensor Networks

Journal of

Control Science

and Engineering
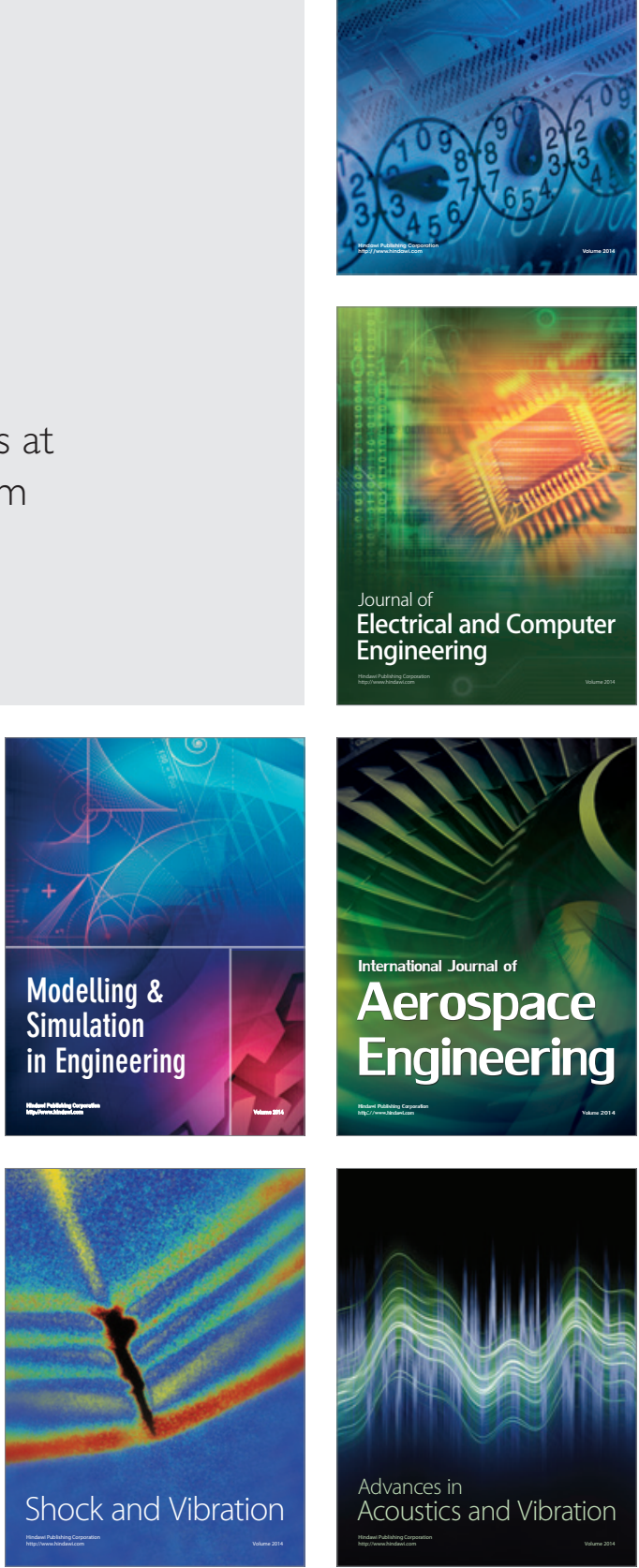